\title{
Acyl CoA binding proteins are required for cuticle formation and plant responses to microbes
}

\author{
Ye Xia ${ }^{1}$, Keshun Yu ${ }^{1}$, Qing-ming Gao ${ }^{1}$, Ella V. Wilson ${ }^{1}$, Duroy Navarre ${ }^{2}$, Pradeep Kachroo ${ }^{1}$ and \\ Aardra Kachroo ${ }^{1 *}$
}

${ }^{1}$ Department of Plant Pathology, University of Kentucky, Lexington, KY, USA

2 U.S. Department of Agriculture, Agricultural Research Service, Washington State University, Prosser, WA, USA

\section{Edited by:}

Xuemin Wang, University of

Missouri-St Louis, USA

Reviewed by:

Shunyuan Xiao, University of Maryland, USA

Jyoti Shah, University of North Texas USA

\section{*Correspondence:}

Aardra Kachroo, Department of Plant Pathology, University of Kentucky,

Lexington, KY 40546, USA.

e-mail: apkach2@uky.edu
Fatty acids (FA) and lipids are well known regulators of plant defense. Our previous studies have shown that components of prokaryotic (plastidal) FA biosynthesis pathway regulate various aspects of plant defense. Here, we investigated the defense related roles of the soluble acyl CoA binding proteins (ACBPs), which are thought to facilitate the intracellular transport of $F A / l i p i d s$. We show that $A C B P 3$ and 4 are required for maintaining normal lipid levels and that $A C B P 3$ contributes to the lipid flux between the prokaryotic and eukaryotic pathways. We also show that loss of $A C B P 3,4$, or 6 impair normal development of the cuticle and affect both basal and resistance protein-mediated defense against bacterial and fungal pathogens. Loss of $A C B P 3,4$, or 6 also inhibits the induction of systemic acquired resistance (SAR) due to the plants inability to generate SAR inducing signal(s). Together, these data show that ACBP3, ACBP4, and ACBP6 are required for cuticle development as well as defense against microbial pathogens.

Keywords: cuticle, plant defense, acyl CoA binding proteins, systemic acquired resistance, fatty acids

\section{INTRODUCTION}

In plants, de novo synthesis of fatty acids (FA) occurs exclusively in the plastids and is initiated by acetyl CoA carboxylase, which converts acetyl CoA to malonyl-CoA. The malonyl group is transferred from CoA to acyl carrier protein (ACP) carrying a phosphopantetheine prosthetic group to which the growing FA chains are esterified. The malonyl-ACP enters into a series of reactions that eventually result in the formation of 16 and 18 carbon saturated FAs, palmitate (16:0), and stearate (18:0; Ohlrogge and Browse, 1995; Kachroo and Kachroo, 2009). The 18:0 FA is desaturated to oleic acid (18:1) by stearoyl-acyl carrier proteindesaturases (SACPD) and in Arabidopsis the major SACPD isoform is encoded by SSI2 (Kachroo et al., 2001, 2003, 2004, 2007, 2008; Venugopal et al., 2009; Xia et al., 2009; Mandal et al., 2012). The 16:0 and 18:1 FAs either remain inside plastids and enter the prokaryotic glycerolipid synthesis pathway or are exported as CoA thioesters to endoplasmic reticulum (ER) where they participate in glycerolipid synthesis via the eukaryotic pathway. The eukaryotic pathway leads to the synthesis of phospholipids such as phosphatidylcholine (PC), phosphatidylethanolamine (PE), and phosphatidylinositol (PI). The ER and plastids undergo extensive exchange of lipid precursors, including that of diacylglycerol (DAG), which is synthesized at both locations and serves as a precursor for the major plastidal galactolipids, monogalactosyldiacylglycerol (MGDG), and digalactosyldiacylglycerol (DGDG). This exchange and trafficking of lipid precursors requires their transport across various cellular compartments and is likely to involve proteins that can transport lipid precursors or promote physical associations between membranes (Moreau et al., 1998). Acyl CoA binding proteins (ACBPs) comprise one such family of proteins that can transport FA/lipid precursors (Kragelund et al.,
1993; Yurchenko et al., 2009; Yurchenko and Weselake, 2011). The Arabidopsis genome encodes six isoforms of ACBPs, which have been well characterized for their structure, localization, expression, and substrate specificities (Chye, 1998; Li and Chye, 2003; Chen et al., 2008; Xiao and Chye, 2009; reviewed in Yurchenko and Weselake, 2011). ACBP1 and 2 are ankyrin-repeat containing membrane proteins that localize to the plasma membrane, ER, and small intracellular vesicles (Li and Chye, 2003). ACBP3, 4, 5, and 6 are soluble proteins that are present either in the extracellular space (ACBP3), or the cytosol (Xiao et al., 2008). The extracellular localization of ACBP correlates with the presence of a cleavable $\mathrm{N}$-terminal signal sequence. ACBP4 and 5 show $\sim 81 \%$ homology at the amino acid level and contain kelch motifs, which represent potential sites for protein-protein interactions. Consistent with this, ACBP4 interacts with the ethylene-responsive element binding protein (Li et al., 2008), a transcription factor expressed in response to biotic and abiotic stresses (Büttner and Singh, 1997; Li et al., 2008).

Plant response to biotic stress involves the complex interplay of pathways induced by various phytohormones. These pathways interact antagonistically, additively, or synergistically to orchestrate plant defense (Doares et al., 1995; van Wees et al., 2000; Kunkel and Brooks, 2002; Glazebrook et al., 2003; RobertSeilaniantz et al., 2011). Several of these phytohormones, including salicylic acid (SA) play important roles in non-host (species level), race-specific (also termed effector triggered immunity, ETI), and basal [also termed pathogen associated molecular patterns (PAMP) triggered immunity, PTI] resistance (Kachroo and Kachroo, 2007). SA is also important for the induction of systemic acquired resistance (SAR), one of the well studied induced defense responses, which primes for resistance against secondary 
pathogens (Dong, 2001). SAR is accompanied by a local and systemic increase in endogenous SA and the concomitant upregulation of a large set of defense genes, including those which encode pathogenesis related (PR) proteins (Boller et al., 1983; Carr et al., 1987; Loon et al., 1987; Ward et al., 1991; Gaffney et al., 1993; Uknes et al., 1993). SAR involves the generation of a mobile signal in the primary infected leaves, which upon translocation to the distal tissues, activates defense responses resulting in broadspectrum resistance. In cucumber, the production of the mobile signal takes places within 3-6 h of inoculation with avirulent bacterial pathogen in the primary leaves (Smith-Becker et al., 1998). Studies in cucumber and Arabidopsis have shown that the primary infected leaf must remain attached for at least $4 \mathrm{~h}$ post infection for immunity to be induced in the distal tissues (Rasmussen et al., 1991; Chanda et al., 2011). The proper induction of SAR is dependent on several factors, including SA (MeSA; Park et al., 2007), the diterpenoid, dehydroabietylamine (DA, Chaturvedi et al., 2012), the nine carbon (C9) dicarboxylic acid, azelaic acid (AA, Jung et al., 2009), auxin (Truman et al., 2010), and the phosphorylated sugar, glycerol-3-phosphate (G3P, Chanda et al., 2011; Mandal et al., 2011). JA has been suggested to participate in SAR (Truman et al., 2007) as well, although its precise role remains debatable (Chaturvedi et al., 2008; Attaran et al., 2009; Xia et al., 2010).

The successful induction of SAR also requires an intact cuticle, a hydrophobic layer that covers the aerial surfaces of the plant (Xia et al., 2009, 2010). The cuticle layer in Arabidopsis leaves is composed of cuticular waxes and cutin monomers and fatty acid (FA) flux plays an important role in their formation. The plastidal C16 and C18 FAs are exported outside plastids and extended to very long chain FAs (VCLF) in the ER compartment. The VLCFAs are converted into cuticular waxes either by deactivation of acylCoA thioesters to release FAs, by conversion of aliphatic esters via the condensation of an acyl moiety with a primary alcohol, or via reductive pathways that convert acyl-CoAs to primary alcohols or aldehydes (see review by Kachroo and Kachroo, 2009). Alkanes, which are the major components of cuticular wax, are generated from aldehydes and are subsequently converted to secondary alcohols and ketones. Cutin component of cuticle is formed by the polymerization of hydroxy group of C16 and C18 $\omega$-hydroxy FAs with the carbonyl group of another monomer (Molina et al., 2006; Pollard et al., 2008). Cutin biosynthesis is also dependent on FA oxidases, acyl-activating enzymes, and acyltransferases. Detailed characterization of two cuticle defective mutants, acp 4 and glabrous $(g l) 1$ has shown that the cuticle defect impairs the plant's ability to respond to the mobile SAR signal but does not affect its ability to generate it (Xia et al., 2009, 2010). Consistent with this result, mechanical abrasion of cuticle of distal leaves compromised SAR in wild-type (wt) plants (Xia et al., 2009). The SAR defect in acp 4 plants is likely not associated with their reduced FA pool. This is because mutations in different membrane-localized FA desaturases (introduce double bonds in specific FAs of membrane lipids; e.g., FAD2, FAD3, FAD7, FAD8) reduce the levels of corresponding FAs but do not inhibit the induction of SAR (Xia et al., 2010). The precise contribution of cuticle in SAR mobile signal perception remains unknown.

The fact that plant cuticle comprises a complex mixture of VLCFA derivatives formed upon elongation of plastidal C16 and
C18 FAs suggests that lipid/FA trafficking might play an important role in cuticle development. Based on this assumption, we evaluated the roles of ACBP3, ACBP4, and ACBP6 in cuticle development and thereby plant defense. We show that mutations in $A C B P 3, A C B P 4$, or ACBP6 impair normal development of the cuticle to varying levels and affect both basal and race-specific defense against microbial pathogens. These $a c b p$ mutants are also defective in SAR. However, unlike acp 4 and $g l 1$ plants, the $a c b p$ mutants were competent in the perception of SAR signal but compromised in its generation. Our data suggest that ACBP3, ACBP4, and ACBP6 may be involved in the transport of FAs and/or lipid species required for the proper development of the plant cuticle as well as the generation of the mobile SAR signal.

\section{RESULTS}

\section{THE acbp3 AND acbp4 PLANTS ARE AFFECTED IN LIPID METABOLISM}

We hypothesized that $A C B P 3, A C B P 4, A C B P 5, A C B P 6$, which encode soluble proteins, were likely to play a role in FA/lipid flux. The encoded proteins are predicted to localize to the cytoplasm (ACBP4, 5, and 6) or the extracellular space (ACBP3; Xiao and Chye, 2009). We attempted to isolate knock-out (KO) lines in each of these genes but were only able to isolate homozygous T-DNA insertions in ACBP3 (At4g24230), ACBP4 (At3g05420), and ACBP6 (At1g31812) genes. Similar lines were used in previous studies where the KO mutations were confirmed by functional complementation with the respective wt gene (Chen et al., 2008; Xiao et al., 2008, 2010). The KO mutations were verified by RTPCR, which confirmed the absence of detectable transcripts in the respective lines (Figure A1 in Appendix). All acbp mutant plants showed wt-like morphology (data not shown) and wt-like FA profiles (Figure 1A). The ACBP KO plants also showed wt-like levels of long chain FAs (data not shown). Interestingly, in contrast to their FA profiles, the $a c b p 3$ and $a c b p 4$ mutant plants showed significant reduction in their total lipid levels, whereas acbp6 plants accumulated wt-like levels of total lipids (Figure 1B). Analysis of individual lipid levels showed reduced levels of MGDG, DGDG, PG, PC, PE, and PI in $a c b p 3$ and reduced levels of MGDG, DGDG, PG, and PI in acbp4 plants (Figure 1C). Analysis of FA species present on the plastidal lipids MGDG or DGDG lipids showed that $a c b p 3$ and $a c b p 4$ plants were reduced in lipid subspecies that were either made in plastids (contain 16:3 and 18:3 FAs) or imported from outside (both FA species are C18; Figure A2 in Appendix). Together, these results indicate that $A C B P 3$ and 4 contribute to membrane lipid synthesis and the lipid flux between the prokaryotic and eukaryotic pathways.

\section{THE acbp PLANTS ARE DEFECTIVE IN THEIR CUTICLE}

To test if the altered lipid levels in $a c b p 3$ and $a c b p 4$ plants impaired cuticle formation, we analyzed the cuticular phenotypes of these plants. We first stained wt and $a c b p$ leaves with toluidine blue, a hydrophilic dye that only penetrates leaves with permeable cuticles (Tanaka et al., 2004). Toluidine blue penetrated acbp3 and acbp4 leaves, staining these blue, suggesting cuticular permeability (Figure 2A; Figure A3A in Appendix). Interestingly, toluidine blue also stained acbp6 leaves, although the staining was less intense. The adaxial surface of all $a c b p$ mutant plants stained more compared to the abaxial surfaces (Figure 2A; Figure A3A in Appendix). 

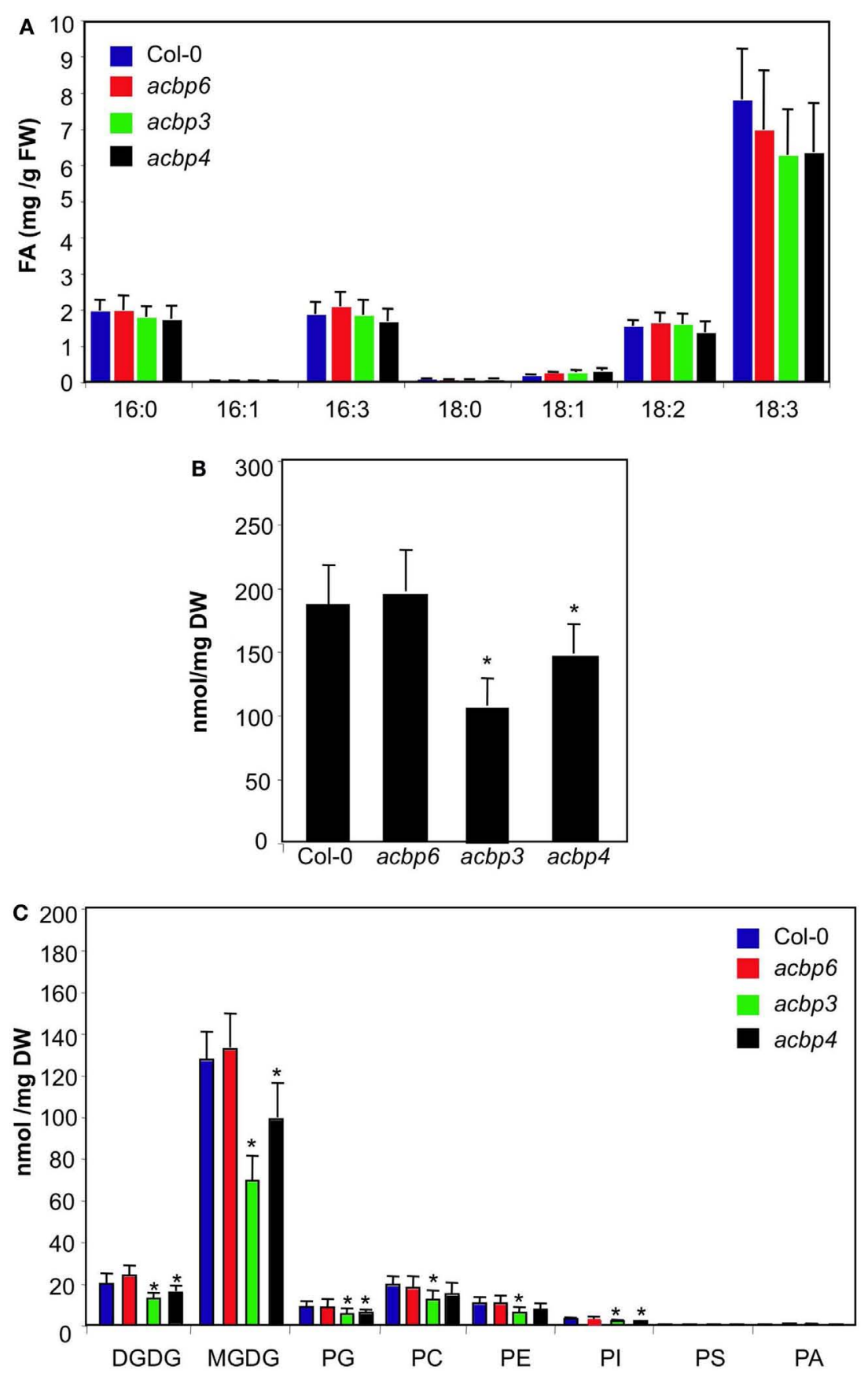

FIGURE 1 | FA and lipid levels in ACBP KO plants. (A) Levels of total FAs in 4-week-old Col-0 and acbp mutant plants. The values are presented as mean of six to eight replicates. FW indicates fresh weight. The error bars represent SD. The experiment was repeated five times with similar results. (B) Total lipid levels in Col-0 and acbp mutant plants. The values are presented as a mean of five replicates. The error bars represent SD. Asterisks denote a significant difference with Col-0 (t-test, $P<0.05$ ). DW indicates dry weight. (C) Profile of total lipids extracted from Col-0 and acbp mutant plants. The values are presented as a mean of five replicates. The error bars represent SD. Asterisks denote a significant difference with Col-0 ( $t$-test, $P<0.05$ ). Symbols for various components are: DGD, digalactosyldiacylglycerol; MGD, monogalactosyldiacylglycerol; PG, phosphatidylglycerol; PC,

phosphatidylcholine; PE, phosphatidylethanolamine; PI, phosphatidylinositol; PS, phosphatidylserine; PA, phosphatidic acid.
Moreover, $a c b p$ mutants showed considerably less staining compared to $f a d 7-1$ gll leaves (Figure A3A in Appendix), suggesting that the cuticular defects of $a c b p$ mutants were likely less pronounced than that of the fad7-1 gll plants. Increased permeability to toluidine blue correlated with water lost from the leaves when subjected to drought stress (Figure 2B); consistent with increased toluidine blue staining, the $a c b p 3$ plants lost more water followed by $a c b p 4$ and $a c b p 6$ plants. Similarly, acbp3 plant showed highest 
leaching of chlorophyll followed by acbp4 and acbp6 (Figure A3B in Appendix).

To confirm that the cuticle is indeed defective in acbp leaves, we analyzed the outermost cell wall of the epidermis by transmission electron microscopy (TEM). As expected, the cuticle of wt leaves appeared as a continuous and regular electron-dense osmophilic layer outside the cell wall (Figure 2C, marked by an arrow). In comparison, the cuticle of $a c b p 4$ and $a c b p 6$ mutants showed both electron-dense and -opaque regions. Strikingly, the cuticle of acbp3 plants was thin, highly irregular, and electronopaque. Scanning electron micrograph (SEM) analysis of wt and acbp leaf surfaces showed increased folding on the adaxial surface (Figure 2D, left panels). In comparison, their abaxial surfaces did not exhibit obvious alterations (Figure 2D, right panels).

To determine if this defect in cuticle structure was associated with alterations in the content and/or composition of cuticular waxes or cutin polyester monomers, we compared levels of waxes and cutin monomers of wt and $a c b p$ leaves. Notably, all

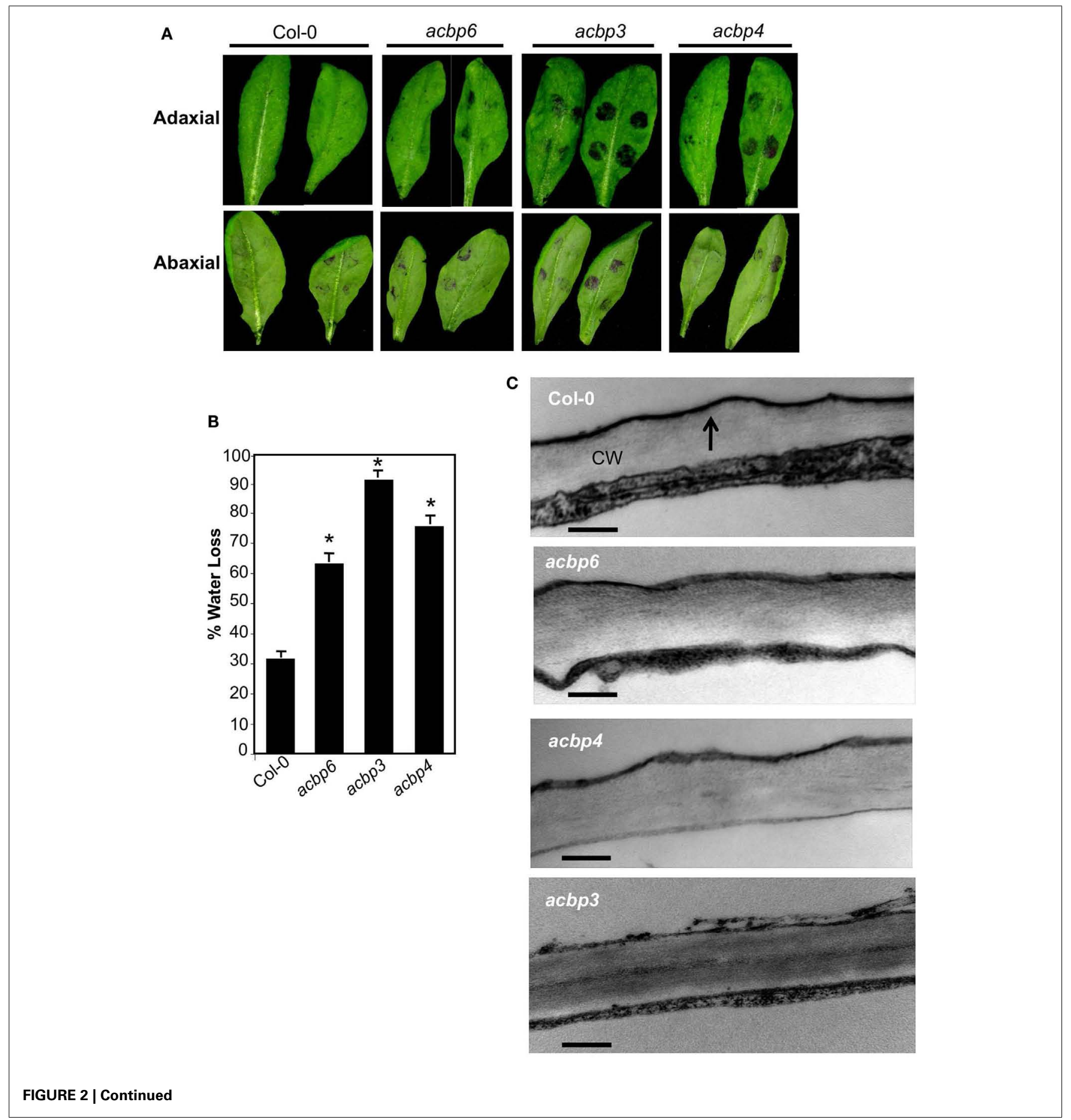



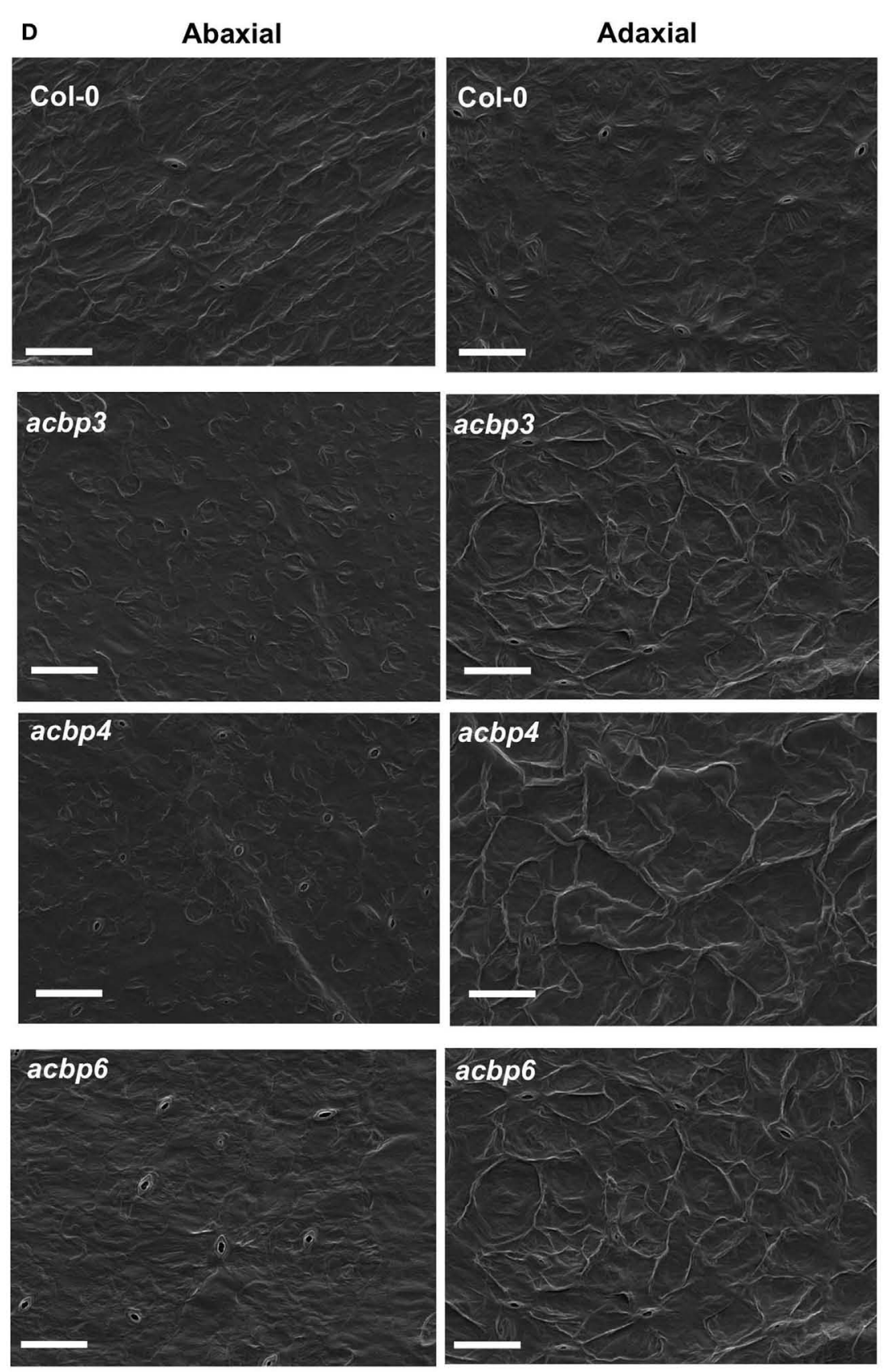

FIGURE 2 | Evaluation of cuticle associated phenotypes in acbp mutant plants. (A) Toluidine blue stained leaves from 4-week-old plants. The stain was spotted on the adaxial or abaxial surface of the leaves and the leaves were washed with water after 20 (left) or 40 min (right) incubations. The experiment was repeated three times with similar results. (B) Measurement of water lost from the leaves subjected to drought conditions for 4 days. The error bars represent SD $(n=25)$. Asterisks denote a significant difference with Col-0 (t-test, $P<0.05$ ). The experiment was repeated three times with similar results. (C) Transmission electron micrographs showing cuticle layer on adaxial surface of leaves from indicated genotypes. At least two independent leaves were sectioned and analyzed. Arrows indicate cuticle. CW indicated cell wall (scale bars, $50 \mathrm{~nm}$ ). (D) Scanning electron micrographs showing adaxial (left panel) and abaxial (right panel) surface of leaves from indicated genotypes (scale bars, $200 \mu \mathrm{M}$ ). Two-three independent leaves were analyzed per genotype. acbp mutants showed significant increases in FA (16:0, 18:0), alkanes (C29, C31, and C33), and primary alcohols $(\mathrm{C} 28-\mathrm{OH}$, $\mathrm{C} 32-\mathrm{OH}$ ) compared to wt plants (Figure 3A). In contrast to cuticular wax, $a c b p 3$ and 4 plants showed greatly reduced levels of cutin monomers (Figure 3B). The decrease was more pronounced in three major monomers, 16:0-, 18:1-, and 18:2-dicarboxylic acids (DCA). Although, the acbp6 plants showed nominal increase in 18:1-DCA, the levels of most other cutin monomers were similar to 

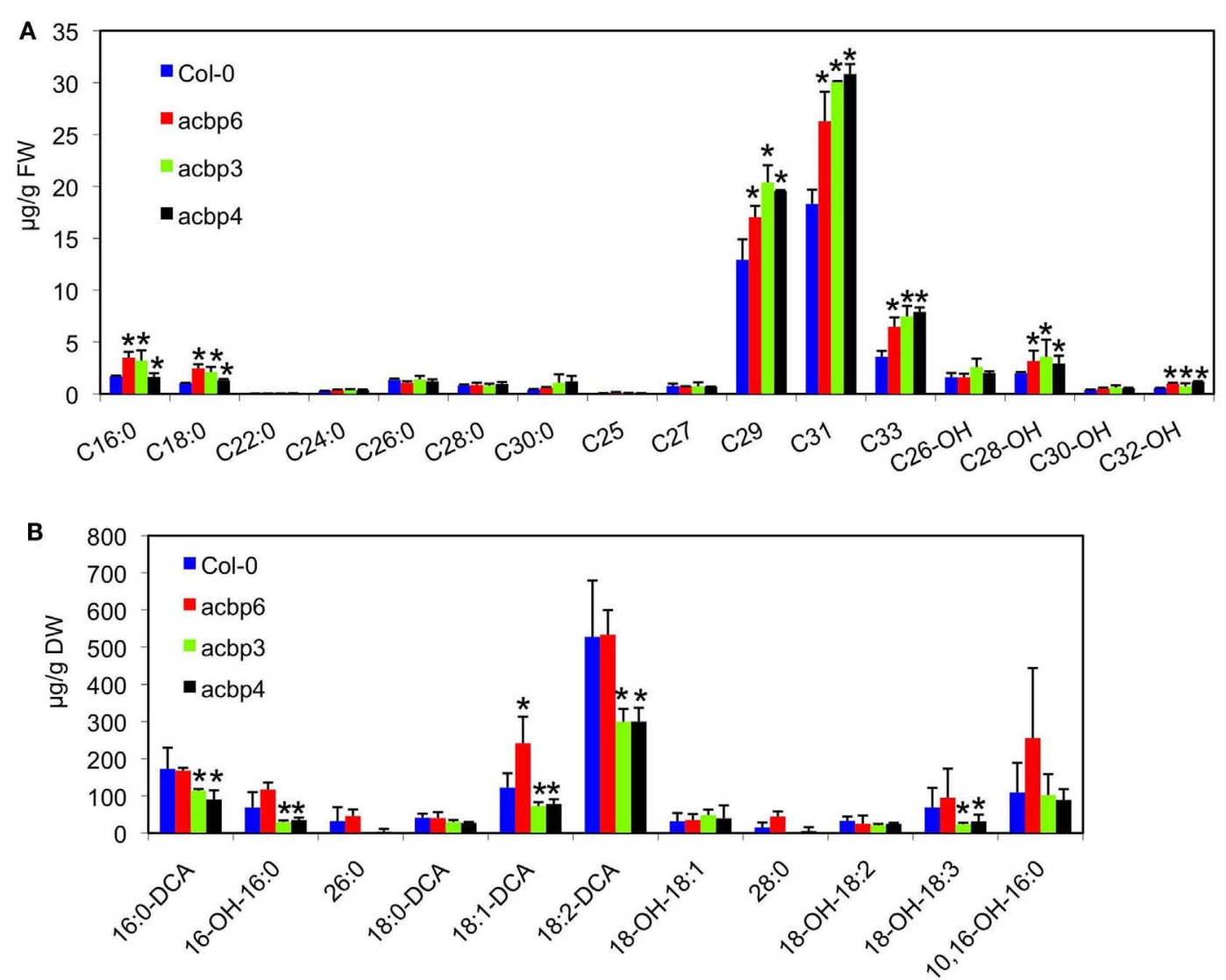

FIGURE 3 | Biochemical profiles of cuticular wax and cutin monomers in acbp mutant plants. (A) Analysis of wax components from leaves of 4-week-old Col-0 and acbp plants. C16:0-C30:0 are FAs, C25-C33 are alkanes, $\mathrm{C} 26-\mathrm{OH}-\mathrm{C} 32-\mathrm{OH}$ are primary alcohols. The values are presented as a mean of five replicates. The error bars represent SD. Asterisks denote a significant difference with $\mathrm{Col}-0$ ( $t$-test, $P<0.05$ ). DW indicates dry weight. (B) Analysis of lipid polyester monomer content of 4-week-old Col-0 and acbp plants. Error bars in $(\mathbf{A}, \mathbf{B})$ represent SD. Statistical significance was calculated using Student's $t$-test ( $t$-test, $P<0.05$ ). Symbols for various components are: 16:0-DCA, 1,16-hexadecane dioic acid; 16-OH-16:0, 16-hydroxyhexadecanoic acid; 10,16-OH-16:0, 10,16-dihydroxyhexadecanoic acid; 18:0-DCA, 1,18-octadecane dioic acid; 18:1-DCA, 1,18-octadecene dioic acid; 18-OH-18:1, 18-hydroxyoctadecenoic acid, 18:2-DCA, 1,18-octadecadiene dioic acid; 18-OH-18:2, 18-hydroxyoctadecadienoic acid; 18-OH-18:3, 18-hydroxyoctadecadienoic acid. that of wt plants. Increased biosynthesis of cuticular components has also been observed in several Arabidopsis mutants that show abnormal cuticle (Schnurr et al., 2004; Kurdyukov et al., 2006; Bessire et al., 2007; Voisin et al., 2009). Together, these data suggest that loss of $A C B P 3,4$, and 6 leads to varying levels of cuticular defects.

\section{THE acbp PLANTS SHOW COMPROMISED SAR AND RESISTANCE TO FUNGAL AND BACTERIAL PATHOGENS}

Since cuticle plays an important role in defense against fungal pathogens, we next evaluated the response of $a c b p 3, a c b p 4$, acbp6 mutants to the necrotrophic pathogen Botrytis cinerea and a hemibiotrophic fungal pathogen Colletotrichum higginsianum. Interestingly, in the majority of experiments, $a c b p$ mutants showed enhanced susceptibility to $B$. cinerea and C. higginsianum; spray and spot inoculations showed significantly larger lesions on $a c b p$ leaves (Figures 4A,B; Figure A4 in Appendix). However, in two of five experiments no noticeable difference in infection symptoms was observed between Col-0 and $a c b p$ mutants (see Figure legends for detail). In comparison, all acbp plants consistently showed enhanced susceptibility to virulent (DC3000) and avirulent (avrRpt2) strain of the bacterial pathogen Pseudomonas syringae (Figures 4C,D). Together, these data suggested that loss of $A C B P 6, A C B P 3$, and $A C B P 4$ impaired basal and race-specific defense against fungal and bacterial pathogens.

Previously, we showed that intact cuticle is required for the normal induction of systemic immunity in plants (Xia et al., 2009, 2010). To determine if the cuticle defect in acbp plants affected systemic immunity, we next tested their abilities to induce SAR. The plants were first infiltrated with $\mathrm{MgCl}_{2}$ or an avirulent strain of P. syringae (avrRpt2), $48 \mathrm{~h}$ later distal leaves of both sets of plants were challenged with a virulent strain of $P$. syringae (DC3000). The proliferation of virulent bacteria was monitored at 0 and $3 \mathrm{dpi}$. The wt plants previously inoculated with avrRpt 2 P. syringae, showed $\sim 10$-fold reduced growth $(P<0.0001)$ of virulent bacteria compared to plants previously infiltrated with $\mathrm{MgCl}_{2}$ (Figure 5A). In contrast, the acbp plants showed only $\sim 1$ - to 1.5 -fold reduction in the growth of virulent bacteria at $3 \mathrm{dpi}$ (these differences were 
A

Mock

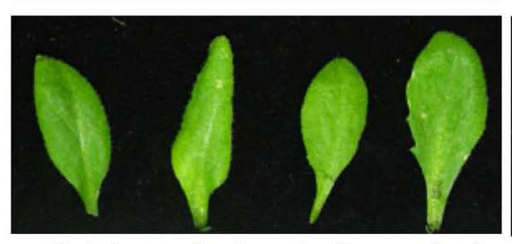

Col-0 acbp6 acbp3 acbp4
C. higginsianum

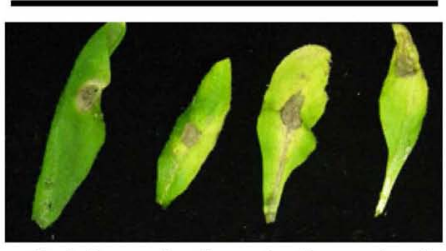

Col-0 acbp6 acbp3 acbp4

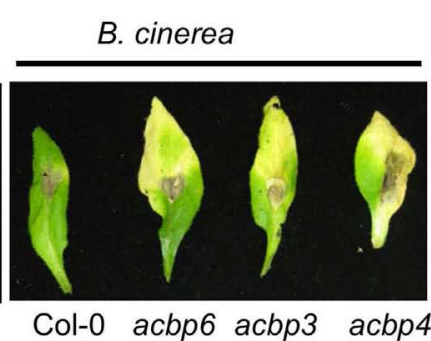

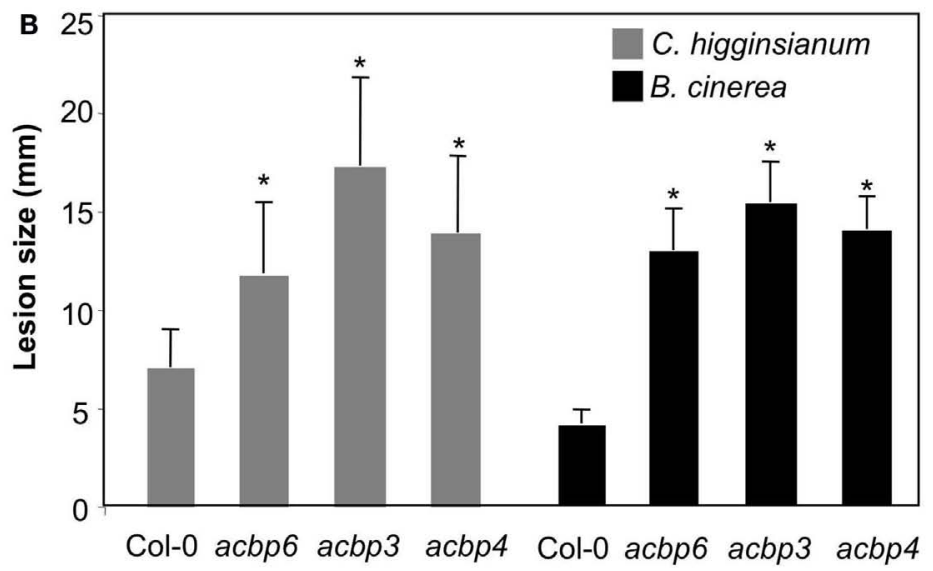

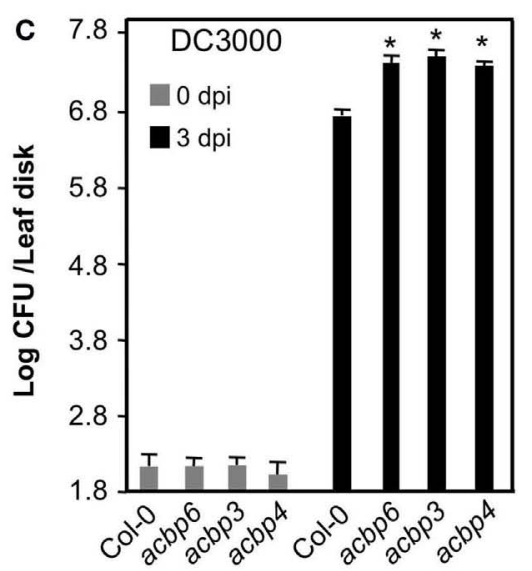

FIGURE 4 |The acbp mutant plants show compromised response to fungal and bacterial pathogens. (A) Disease symptoms on indicated genotypes spot-inoculated with water or $10^{6} \mathrm{spores} / \mathrm{ml}$ of $C$. higginsianum or B. cinerea. The experiment was carried out five times and three of these showed enhanced susceptibility in acbp plants. (B) Lesion size in spot-inoculated genotypes. The plants were spot-inoculated with $10^{6} \mathrm{spores} / \mathrm{ml}$ of $C$. higginsianum and the lesion size was measured from 20 to 30 independent leaves at 6 dpi. Statistical significance was determined using Student's $t$-test. Asterisks indicate data statistically significant from that

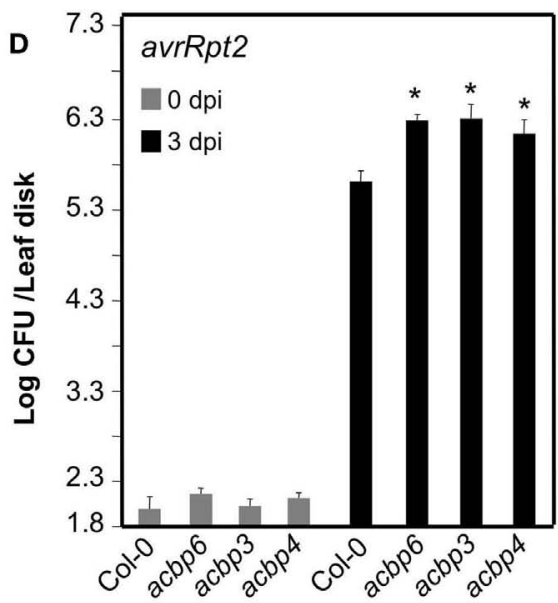

of control (Col-0; $P<0.05)$. Error bars indicate SD. (C) Growth of virulent $P$. syringae on leaves from Col-0 or acbp mutant plants. Error bars indicate SD. Asterisks indicate data statistically significant from that of control (Col-0; $P<0.05, n=4)$. (D) Growth of avirulent (avrRpt2) P. syringae strains on Col-0 or acbp mutant plants. Error bars indicate SD. Asterisks indicate data statistically significant from that of control (Col-0; $P<0.05, n=4)$. Bacterial growth presented as the LOG of colony forming units (CFU) per leaf disk, was monitored at 0 and 3 dpi. Experiments in $(\mathbf{C}, \mathbf{D})$ were repeated six times each with similar results. not statistically significant), when pre-exposed to avrRpt2 bacteria. Thus, all $a c b p$ mutant plants were defective in their ability to induce SAR.

The cuticular defect in acp 4 plants impairs their ability to perceive the SAR signal but not their ability to generate the mobile SAR signal. To test if this were also the case with the acbp mutants, we evaluated the response of wt and $a c b p$ plants to petiole exudates collected from pathogen infected leaves of wt and $a c b p$ mutant plants. The wt or $a c b p$ leaves were infiltrated with $\mathrm{MgCl}_{2}$ or $a v r$ $R p t 2$ bacteria and petiole exudates collected from these leaves were injected into the leaves of a fresh set of wt and the corresponding acbp mutant plants. Distal leaves of the exudate-infiltrated plants 
were then inoculated with virulent bacteria and proliferation of virulent bacteria monitored at 0 and $3 \mathrm{dpi}$ (Figures 5B-D). As expected, exudates from avrRpt2-infected wt plants conferred protection against virulent pathogen in wt plants $(P<0.0001)$. The exudates from wt plants also conferred protection against virulent pathogen in $a c b p$ plants $(P<0.0001)$, suggesting that $a c b p$ plants were able to perceive the SAR signal. In contrast to wt, exudates from avrRpt2-infected acbp plants were unable to confer SAR in wt or respective $a c b p$ plants, suggesting that $a c b p$ plants are defective in generating the mobile SAR signal. To determine if this was
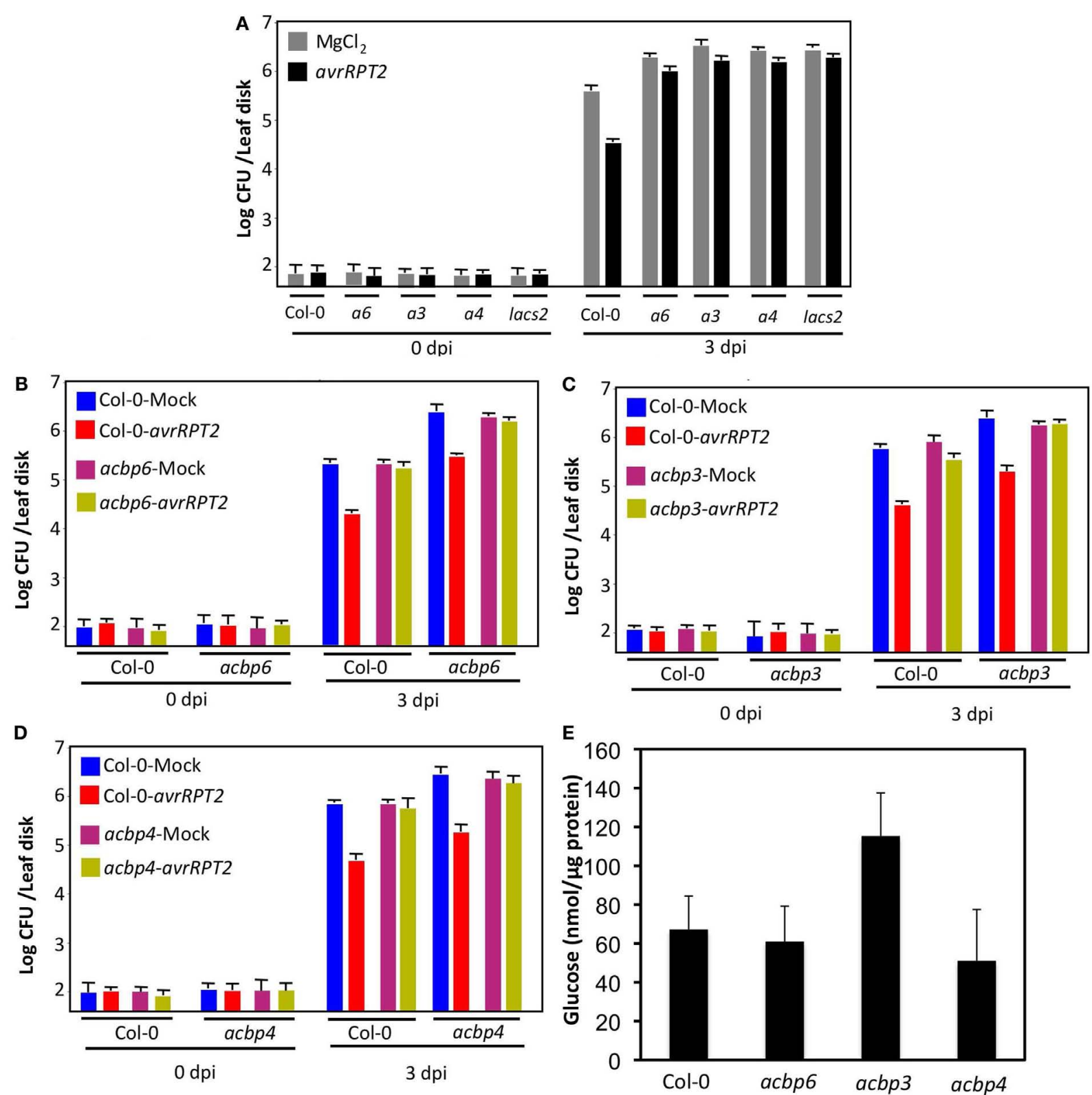

FIGURE 5 |The acbp mutants show compromised SAR. (A) SAR response in Col-0 and acbp6 (a6), acbp3 (a3), acbp4 (a4), and lacs2 plants. Primary leaves were inoculated with $\mathrm{MgCl}_{2}$ (gray bars) or $P$. syringae containing avrRpt2 (black bars). The distal leaves were inoculated with the virulent $P$. syringae and growth of the virulent bacteria was monitored at $3 \mathrm{dpi}$. The SAR impaired lacs2 plants were used as a positive control (Xia et al., 2009). This experiment was repeated six times with similar results. Asterisk denotes significant difference from plants of the same genotype pre-infiltrated with $\mathrm{MgCl}_{2}$ ( $t$-test, $n=4, P<0.0001$ ). (B-D) SAR response in Col-0 and acbp plants infiltrated with exudates (Ex) collected from wt or acbp plants that

were treated either with $\mathrm{MgCl}_{2}$ (blue and pink bars) or $P$. syringae expressing avrRpt2 (red and yellow bars). Error bars indicate SD $(n=4)$. Statistical significance was calculated using Student's $t$-test $(P<0.0001)$. Experiments shown in (B-D) were repeated twice with similar results. Bacterial growth presented as the LOG of colony forming units (CFU) per leaf disk, was monitored at 0 and 3 dpi. (E) Glucose levels in petiole exudates collected from indicated genotypes. Error bars indicate SD. The experiment was repeated twice and the second repeat showed wild-type-like glucose levels in acbp3 plants. Error bars indicate SD $(n=3)$. No statistical significance was observed in the levels from different genotypes per Student's $t$-test. 
due to defective exudation, we monitored glucose levels in petiole exudates collected from wt and acbp plants. Petiole exudates collected from untreated plants showed wt-like levels of glucose in $a c b p$ plants (Figure 5E), suggesting that acbp plants are not defective in the exudation process. A higher level of glucose seen in $a c b p 3$ petiole exudates was only seen in one of two experiments, and was not statistically significant. Together, these results suggest that $a c b p$ plants are defective in the generation of SAR signal but competent in its perception. Interestingly, this phenotype is just the reverse of that observed in other cuticle defective acp 4 and $g l 1$ plants, which are defective in perception of the SAR signal (Xia et al., 2009, 2010).

Since SA plays a critical role in basal, R-mediated resistance, and SAR, we next tested if the $a c b p$ mutant plants were competent in pathogen responsive accumulation of SA. SA levels in wt and $a c b p$ plants were determined before and after inoculation of $P$. syringae expressing avrRpt2. As expected, wt plants inoculated with avirulent pathogen showed a significant increase in both free SA and SA glucoside (SAG) in their primary (inoculated) as well as distal uninoculated tissues. Although the $a c b p$ plants also showed an increase in SA and SAG levels in the primary tissues, levels of SA/SAG in these were significantly lower compared to wt plants (Figure 6A). Thus, impaired SAR in $a c b p$ plants correlated with their inability to accumulate SA. The acbp mutants were responsive to SA or its biologically active analog BTH [benzo $(1,2,3)$ thiadiazole-7-carbothioic acid] and induced wt-like expression of the marker gene $P R-1$ (Figure 6B, data shown for BTH treatment). This suggested that the $a c b p$ mutants were sensitive to exogenous SA and the compromised local defenses and SAR in acbp mutants was not related to perception of SA. We next assayed the effect of exogenously supplied BTH on basaland R-mediated resistance and SAR. The wt and acbp plants were treated with BTH for $48 \mathrm{~h}$ prior to mock or pathogen inoculations. Exogenous whole plant BTH application increased local resistance against both virulent and avirulent pathogens in wt and $a c b p$ mutants (Figure A5 in Appendix, $P<0.001$, data not shown for virulent pathogen). In contrast, and unlike wt plants, BTH pretreated mock- and avrRpt2 inoculated plants supported similar growth of virulent bacteria, suggesting that BTH treatment was unable to confer SAR in acbp plants even though it did improve resistance compared to water-treated plants (Figure 6C). To test this further, we collected petiole exudates from wt and acbp leaves that were infiltrated with $\mathrm{MgCl}_{2}$ (mock) or avrRpt2 bacteria and mixed these with water, BTH, or SA prior to infiltrating these into the primary leaves of a fresh set of wt and $a c b p$ plants. The distal leaves of this second set of plants were then inoculated with virulent bacteria and proliferation of the virulent bacteria monitored at 0 and $3 \mathrm{dpi}$ (Figure 6D-F, see Figure A6 in Appendix for SA related data). As expected, exudates from avrRpt2-infected wt plants conferred protection against virulent pathogen in wt plants (compare pink and blue bars in Ex-Col-0 treatment for each genotype $P<0.005)$. Similarly, exudates from avrRpt2-infected wt plants also conferred protection against virulent pathogen in $a c b p 3, a c b p 4$, and $a c b p 6$ plants, thus confirming their inability to generate SAR signal (Figures 5B-D, $P<0.0001$, compare blue and red bars for each genotype). In contrast, petiole exudates from avrRpt2-infected $a c b p 3$, $a c b p 4$, or acbp6 plants were unable to confer resistance against virulent pathogen in wt plants or themselves (Figures 6D-F, compare pink and blue bars in Ex-a3/a4/a6 treatment for each genotype, also see Figures 5B-D). The BTH containing exudate from $\mathrm{MgCl}_{2}$-infiltrated wt plants (red bars) conferred SAR only on wt plants $(P<0.005)$, whereas BTH containing exudate from avrRpt2-infiltrated wt plants (yellow bars) conferred SAR on both wt and acbp plants $(P<0.005)$. Notably, BTH slightly improved the SAR induced by avrRpt2-infiltrated wt exudate only on wt plants $(P<0.01$, compare pink and yellow bars for each genotype infiltrated with Ex-Col-0). In comparison, the BTH containing exudate from $\mathrm{MgCl}_{2}$ - or avrRpt2-infiltrated $a c b p$ plants was unable to confer SAR on either Col-0 or $a c b p$ plants. This suggested that the proper induction of SAR required a factor that was present in pathogen infected Col-0 exudates but absent in exudates from pathogen infected $a c b p$ plants. These data reconfirm that $a c b p$ mutants are defective in the generation of the mobile signal but not its perception and that SA alone is not sufficient for the induction of SAR.

Recently, a dicarboxylic acid, azelaic acid (AA) was shown to confer SAR by priming biosynthesis of SA (Jung et al., 2009). To test if reduced accumulation of SA in $a c b p$ plants was due to compromised AA biosynthesis/accumulation, we monitored AA levels in mock- and pathogen inoculated wt and $a c b p$ petiole exudates (Figure 7A). The wt-like basal and pathogen-induced AA levels in $a c b p$ plants suggest that these are not altered in the biosynthesis and/or accumulation of AA. We next tested if $a c b p$ mutants were capable of converting the biologically inactive MeSA to SA, since conversion of the methylated ester of SA (MeSA) to SA is also critical for SAR (Seskar et al., 1998; Park et al., 2007). The wt and $a c b p$ plants were treated with MeSA for $48 \mathrm{~h}$ and evaluated for $P R-1$ expression and SAR. The $a c b p$ mutants induced wt-like expression of $P R-1$ in response to exogenous application of MeSA (Figure 7B), suggesting that these plants are capable of converting MeSA to SA. This was further supported by the fact that MeSA treated $a c b p$ mutants showed increased resistance against virulent pathogen (Figure 7C, $P<0.005$ ). Together, these results suggest that compromised SA levels in pathogen inoculated acbp mutants were not due to defects in AA metabolism or the release of SA from the MeSA pool.

\section{DISCUSSION}

The Arabidopsis genome encodes six ACBPs, which localize to different cellular compartments. This study evaluated the defense related roles of $A C B P 3, A C B P 4$, and $A C B P 6$ gene products, which are well known to bind FA-CoA and/or various lipids (Xiao and Chye, 2009; Xiao et al., 2010), and are likely involved in their transport. We show that $A C B P 3, A C B P 4$, and $A C B P 6$ are required for basal resistance to fungal pathogens and, both basal (PTI) and $R$-mediated (ETI) resistance to bacterial pathogens. Notably, the $a c b p 3, a c b p 4$, and $a c b p 6$ mutants are also defective in the induction of SAR. It is possible that the impaired PTI and/or ETI in these plants affect their abilities to induce SAR. However, it is also likely that the impaired SAR is associated with the defective cuticles in these mutants. This is supported by the fact that defective cuticular phenotype is associated with compromised SAR and bacterial resistance, and in some cases increased susceptibility to fungi as well as. However, unlike other cuticle defective mutants [like acp 

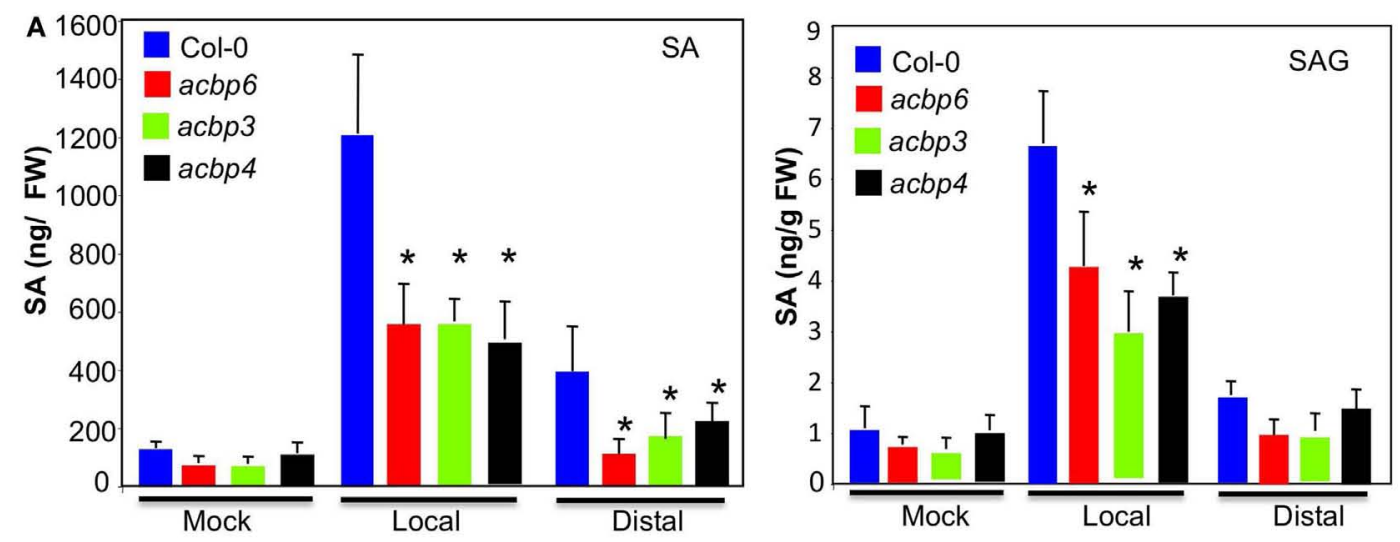

B

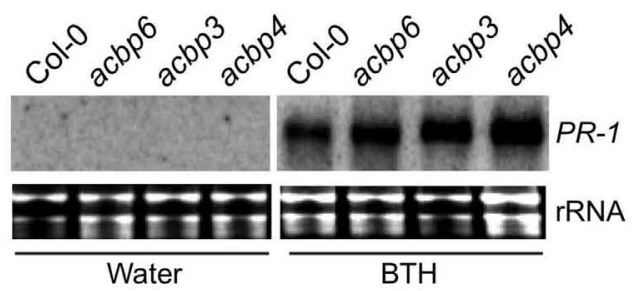

C
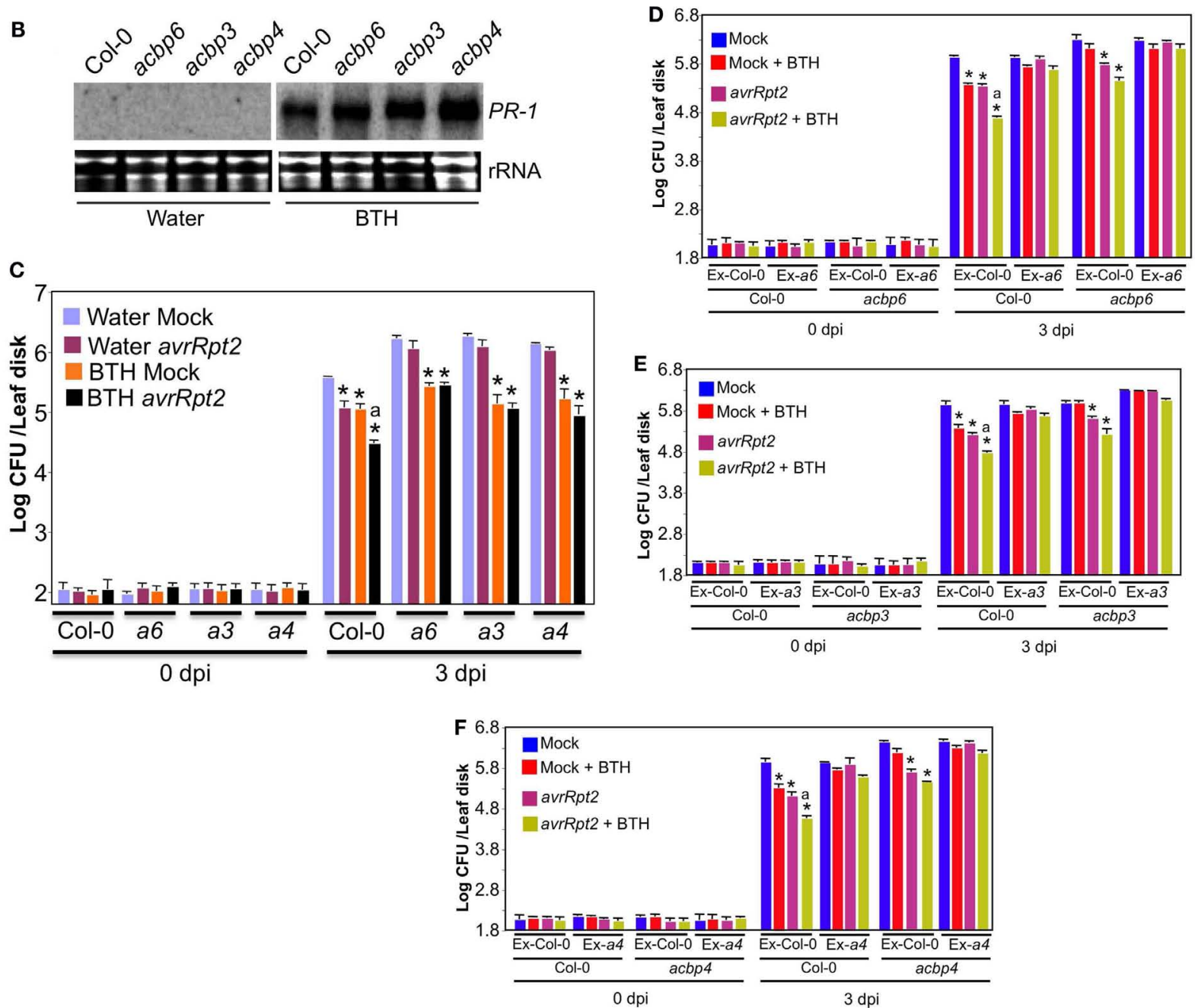

FIGURE 6 |The acbp mutants accumulate reduced levels of SA. (A) SA and SAG levels in local (inoculated) and distal (uninoculated) leaves of Col-0 and acbp plants inoculated with $\mathrm{MgCl}_{2}$ or $P$. syringae expressing avrRpt2. Leaves were harvested at $3 \mathrm{dpi}$. Error bars indicate SD. Asterisks indicate data statistically significant from that of control (Col-0; $P<0.05, n=4)$. The experiment was repeated twice with similar results. (B) RNA gel blot showing transcript levels of $P R-1$ gene in plants treated with water or BTH for $48 \mathrm{~h}$. Ethidium bromide staining of total RNA was used as the loading control. The experiment was repeated twice with similar results. (C) SAR response in Col-0 and acbp plants pretreated with water (purple and pink bars) or the SA analog BTH (orange and black bars) for $48 \mathrm{~h}$ prior to mock (purple and orange bars) or avr (pink and black bars) inoculation. The error bars represent SD $(n=4)$. Asterisks denote statistical differences from water and mock treated plants of corresponding genotype ( $t$-test $P<0.001)$. Statistical difference from BTH and mock treated plants is indicated by "a" $(P<0.001)$. The experiment was repeated three times with similar results. 


\section{FIGURE 6 | Continued}

(D-F) SAR response in Col-0 and acbp plants infiltrated with exudates (Ex) collected from wt or acbp plants that were treated either with $\mathrm{MgCl}_{2}$ (mock, blue, and red bars) or $P$. syringae expressing avrRpt2 (pink and yellow bars). Exudates were mixed with water (blue and pink bars) or $100 \mu \mathrm{M} \mathrm{BTH}$ (red and yellow bars) prior to infiltration into a fresh set of plants. Error bars indicate SD $(n=4)$. Statistical significance was calculated using Student's t-test. Asterisks denote statistical differences from mock + water-treated plants (blue bars) of corresponding genotype ( $t$-test $P<0.005)$. Statistical difference from avrRpt2 + water-treated plants (pink bars) is indicated by "a" $(P<0.01)$. Bacterial growth presented as the LOG of colony forming units (CFU) per leaf disk, was monitored at 0 and 3 dpi. Experiments in (B-D) were repeated twice with similar results. a3, a4, a6 indicate acbp3, acbp4, and acbp6, respectively.
4; and glabara ( $g l$ ) 1; Xia et al., 2009, 2010], acbp plants are able to perceive the SAR mobile signal from wt plants, but cannot generate it themselves. It is possible that the extent of cuticular damage influences the plant's ability to perceive the SAR signal(s) in the distal tissue since the cuticular defects of $a c p 4$ and gll plants are far more severe than those of the acbp mutants. Additionally, some of the specific signal(s) required for generation and/or perception of SAR may also contribute to cuticle development, therefore even though the acp 4 and acbp mutants are defective in different aspects of SAR they each have defective cuticles. The fact that cuticle contains glycerol (Molina et al., 2006; Pollard et al., 2008), which serves as a precursor for the SAR inducer G3P (Chanda et al., 2011), supports such a notion. Another possibility is that generation of the SAR signal(s) requires ACBP-mediated FA/lipid flux. Although this scenario does not explain the SAR defect in acbp6 plants, which showed normal FA/lipid profile, we cannot discount the possibility that changes in the flux of some metabolite(s) were undetectable in our FA/lipid profiling procedures.

Interestingly, similar to $a c b p$ mutants, the cuticle defective fad7 gl1 (but not acp4) mutant is also compromised in pathogeninduced SA levels, even though fad7 gll is competent in SAR signal generation. It is possible that the defect in SA biosynthesis contributes to the enhanced susceptibility of the $a c b p$ mutants to virulent bacteria and fungal pathogens. However, exogenous application of the SA analog, BTH, together with avirulent pathogen was unable to restore SAR in $a c b p$ plants. This is not due to defects in AA biosynthesis or inability to convert MeSA to SA, because the $a c b p$ mutant plants show wt-like responsiveness to MeSA and contain wt-like AA levels. However, the whole plant-treatment experiments done here cannot discount the possibility that $a c b p$ mutants might be defective in MeSA generation in the primary infected leaves. Besides AA and MeSA, G3P, DA, and an amino acid derivative pipecolic acid (Pip), also regulate SAR, where DA and Pip trigger the accumulation of SA (Chaturvedi et al., 2012; Dempsey and Klessig, 2012; Zeier, J., personal communications). The interrelationships between these various SAR signals and their relationship to $S A$ remain unclear. It will be useful to determine the levels of various SAR inducers and test their SAR inducing capabilities in cuticle defective plants.

Interestingly, in contrast to $a c b p$, and gll mutants, the damaged cuticle in lacs $2, l c r$, or fungal cutinase-overexpressing transgenic plants confers increased resistance to the necrotrophic pathogen B. cinerea and Sclerotinia (Bessire et al., 2007; Tang et al., 2007). Likewise, reduced surface hydrophobicity of mutants defective in abaxial epicuticular wax biosynthesis confers increased resistance to rust and anthracnose pathogens because the spores of these pathogens are unable to differentiate on these mutants (Uppalapati et al., 2012). On the other hand, loss of cuticle in the gpat4 gpat8 double mutant is associated with enhanced susceptibility to Alternaria brassicicola (Li et al., 2007). These results suggest that cuticle permeability is not always associated with increased resistance (Voisin et al., 2009), and structural and/or physiological properties of cuticle might play diverse role(s) in different host-pathogen interactions.

Impaired lipid levels in $a c b p 3$ and $a c b p 4$ plants suggest that these ACBPs are required for maintaining normal lipid levels. Mutations in both $A C B P 3$ and $A C B P 4$ result in reduced MGDG, PG, and PC levels. In addition, $a c b p 3$ plants are significantly reduced in MGDG and DGDG derived from the eukaryotic pathway (containing 18:3 species). This suggests that ACBP3 may be involved in the transport of DAG, the precursor of DGDG synthesis, from the ER (site of lipid biosynthesis via eukaryotic pathway) to the plastids (site of lipid biosynthesis via prokaryotic pathway). Both $a c b p 3$ and $a c b p 4$ plants are also affected in 16:3 FA containing MGDG and DGDG lipids, suggesting that these mutations also affect the prokaryotic pathway. Notably, the lipid profile and/or total lipid levels did not correlate with cuticular defects, since the cuticle defective acbp6 plants show wt-like lipid profiles. The fact that mutations reducing total and plastidal lipids MGDG and DGDG do not always affect cuticle formation (Xia et al., 2010; Chanda et al., 2011), suggests that the flux of lipids or lipid precursors, rather than their levels, might be important for cuticle development. This is also consistent with the fact that the defect in cuticle development is more severe in acbp3 mutant plants, which shows highest reduction in plastidal lipids species derived from the eukaryotic pathway. Notably, reduced lipid levels in $a c b p 3$ and $a c b p 4$ mutants are not associated with reduced FA pools. A likely explanation is that $a c b p$ mutants hyper-produce FA species to compensate for their deficiencies. This assumption is supported by the fact that several other cuticle defective mutants (Kurdyukov et al., 2006; Voisin et al., 2009) are hyperactive in the synthesis of cuticle components.

The compromised basal resistance to bacterial pathogen in acbp3 mutant plants is consistent with a recent report showing increased resistance to virulent $P$. syringae in plants overexpressing $A C B P 3$ (Xiao and Chye, 2011). The ACBP3 overexpressing plants accumulated higher basal levels of SA and showed constitutive cell death and $P R$ expression. Consistent with these results, acbp3 mutant plants are unable to accumulate wt-like levels of SA in response to pathogen infection. This in turn is consistent with the reduced expression of pathogen-responsive $P R-1$ in these plants (data not shown). The impaired cuticle of acbp3 mutants is unlikely to be associated with their reduced SA accumulation because, the acp 4 mutant, which also contains defective cuticle, is able to accumulate wt-like levels of SA in response to pathogen infection (Xia et al., 2009). Inoculation with virulent pathogen 

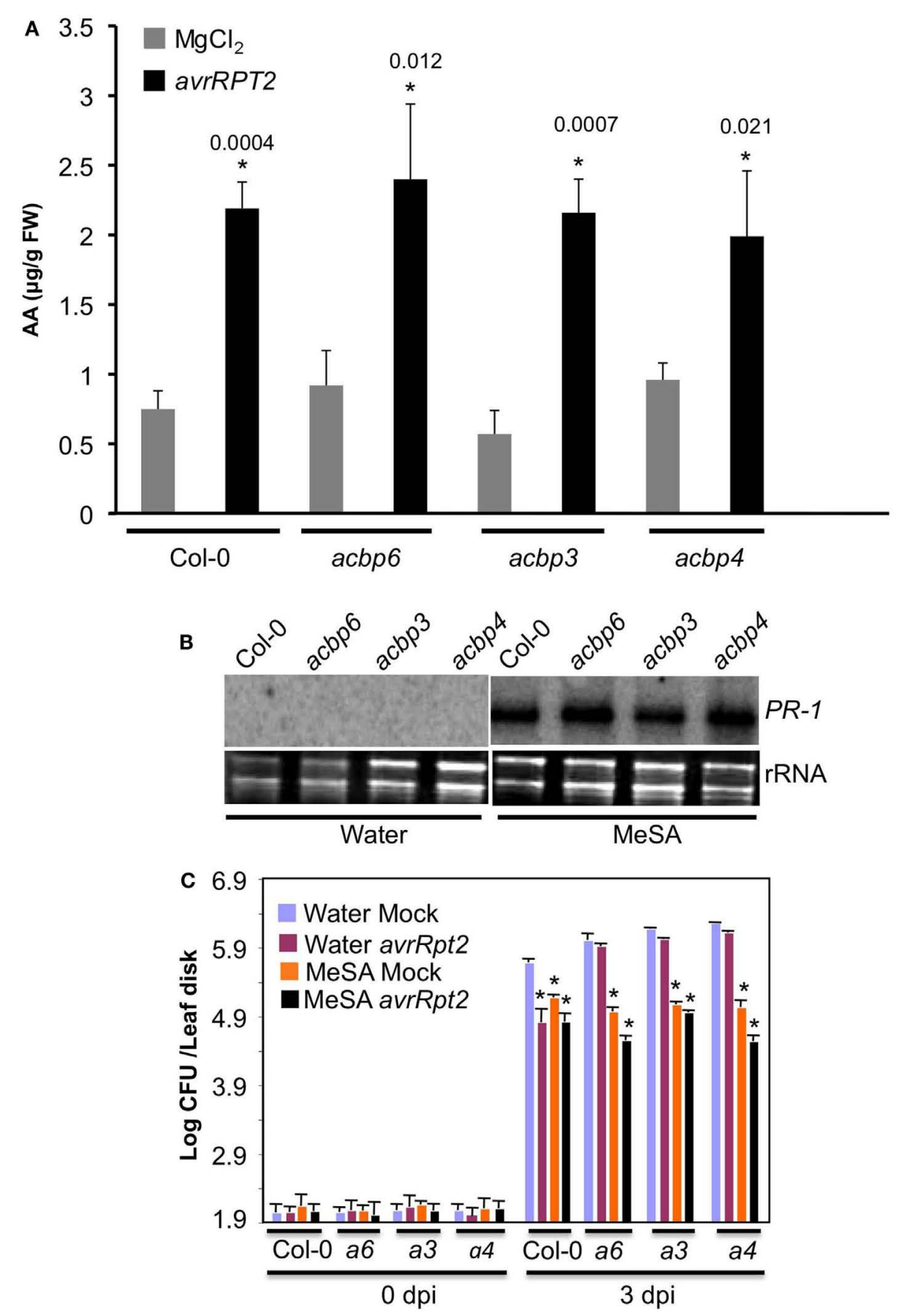

FIGURE 7 |The acbp mutants are responsive to MeSA and accumulate normal levels of AA. (A) AA levels in mock $\left(\mathrm{MgCl}_{2}\right.$, gray bars) and avrRpt2 (black bars) inoculated wild-type (Col-0) and acbp mutants. Error bars indicate SD $(n=3)$. Statistical significance was calculated using Student's $t$-test. Asterisks denote significant differences from mock-inoculated plants of corresponding genotype. Numbers above black bars indicate $P$ values. The experiment was repeated twice with similar results. (B) RNA gel blot showing transcript levels of PR-1 gene in plants treated with water or MeSA for $48 \mathrm{~h}$.
Ethidium bromide staining of total RNA was used as the loading control. The experiment was repeated twice with similar results. (C) SAR response in Col-0 and acbp6 (a6), acbp3 (a3), acbp4 (a4) plants, pretreated with water (blue and pink bars) or $100 \mu \mathrm{M}$ MeSA (orange and black bars) prior to infiltration with $\mathrm{MgCl}_{2}$ (mock, blue, and orange bars) or P. syringae expressing avrRpt2 (pink and black bars). Bacterial growth presented as the LOG of colony forming units (CFU) per leaf disk, was monitored at 0 and 3 dpi. Error bars indicate SD $(n=4)$. Statistical significance was calculated using Student's $t$-test $(P<0.005)$. 
has been suggested to induce degradation and/or relocalization of ACBP3-GFP (Xiao and Chye, 2011), suggesting that ACBP3 might serve as one of the potential pathogen targets, which upon degradation leads to enhanced pathogen growth. Interestingly, $A C B P$ has also been show to participate in senescence; the $a c b p 3$ mutant shows delayed senescence and $A C B P 3$ overexpression accelerated starvation-induced leaf senescence (Xiao et al., 2010). Notably, the accelerated senescence in $A C B P 3$ overexpressing plants was dependent on the SA pathway, which is known to contribute to senescence (reviewed in Vincente and Plasencia, 2011). In this regard, it is interesting to note that delayed senescence is associated with the cuticular defect in the lacerata mutant (Wellesen et al., 2001). Clearly, more work is required to clarify the relationship between the phenotypes related to cuticle, senescence, and transport of FA/lipids in the acbp mutants, and the precise roles of ACBPs in these physiological processes.

\section{MATERIALS AND METHODS PLANT GROWTH CONDITIONS}

Plants were grown in MTPS 144 Conviron (Winnipeg, MB, Canada) walk-in chambers at $22^{\circ} \mathrm{C}, 65 \%$ relative humidity, and $14 \mathrm{~h}$ photoperiod. These chambers were equipped with cool white fluorescent bulbs (Sylvania, FO96/841/XP/ECO). The photon flux density (PFD) of the day period was $106.9 \mu \mathrm{mol} \mathrm{m}^{-2} \mathrm{~s}^{-1}$ (measured using a digital light meter, Phytotronic, Inc, MO, USA). Plants were grown on autoclaved Pro-Mix soil (Premier Horticulture, Inc., PA, USA). Soil was fertilized once using Scotts Peter's 20:10:20 peat lite special general fertilizer that contained 8.1\% ammoniacal nitrogen and $11.9 \%$ nitrate nitrogen (Scottspro.com). Plants were irrigated using deionized or tap water. The $a c b p 3$, $a c b p 4$, and $a c b p 6$ T-DNA mutants were identified from the SALK012290, SALK-040164, and SALK-104339 lines, respectively. The genotypes were determined by PCR. The SALK lines used here have been used in several earlier studies (Chen et al., 2008; Xiao et al., 2008, 2010).

\section{RNA EXTRACTION, NORTHERN, AND PCR ANALYSES}

Small-scale extraction of RNA from one or two leaves was performed in the TRIzol reagent (Invitrogen, Gaithersburg, MD, USA) following the manufacturer's instructions. RNA gel blot analysis and synthesis of random primed probes was carried out as described before (Kachroo et al., 2005). RNA quality and concentration were determined by gel electrophoresis and determination of A260. Reverse transcription (RT) and first strand cDNA synthesis was carried out using Superscript II (Invitrogen). Two to three independent RNA preparations were used for RT-PCR and each of these were analyzed at least twice by RT-PCR. The RT-PCR using gene-specific primers was carried out for 35 cycles in order to determine absolute levels of transcripts.

\section{SA QUANTIFICATION}

SA and SAG were extracted and measured from $\sim 0.3 \mathrm{~g}$ of fresh weight leaf tissue, as described before (Chandra-Shekara et al., 2006). For SA measurements plants were inoculated with $10^{5} / \mathrm{ml}$ bacteria and samples were harvested $48 \mathrm{~h}$ post inoculation. Data presented are a mean of three biological repeats.

\section{AA, FA, LIPID, AND GLUCOSE ANALYSES}

For AA estimations, petiole exudates were extracted using a solution containing glacial acetic acid, methanol, chloroform, and potassium chloride $(0.9 \% ; 1: 4: 8: 8 \mathrm{~V} / \mathrm{V})$ and $17: 0$ as the internal standard. The lower phase was dried under compressed nitrogen and samples were derivatized with MTBSTFA containing 1\% TBDMCS, suspended in acetonitrile and analyzed by gas chromatography (GC) on a Varian FAME $0.25 \mathrm{~mm} \times 50 \mathrm{~mm}$ column equipped with mass spectrometer (MS; Hewlett Packard).

Extraction of total FAs was carried out by placing leaf tissue in $2 \mathrm{ml}$ of $3 \% \mathrm{H}_{2} \mathrm{SO}_{4}$ in methanol. After $30 \mathrm{~min}$ incubation at $80^{\circ} \mathrm{C}$, $1 \mathrm{ml}$ of hexane with $0.001 \%$ butylated hydroxytoluene (BHT) was added. The hexane phase was then transferred to vials for GC analysis. One-microliter samples were analyzed by GC on a Varian FAME $0.25 \mathrm{~mm} \times 50 \mathrm{~mm}$ column and quantified with flame ionization detection. FAs were identified based on their retention time relative to known FA standards. For quantification of FAs, leaves $(50 \mathrm{mg}$ ) were extracted together with an internal standard 19:0 and the FA levels were calculated based on the detected peak areas corresponding to the FA retention time relative to the areas of the internal standard. FA analysis is representative of at least four independent repeats.

For lipid extraction, six to eight leaves were incubated at $75^{\circ} \mathrm{C}$ in isopropanol containing $0.001 \% \mathrm{BHT}$ for $\sim 15 \mathrm{~min}$. To this, $1.5 \mathrm{ml}$ chloroform and $0.6 \mathrm{ml}$ water was added and the samples were agitated at room temperature for $1 \mathrm{~h}$. The lipids were re-extracted in chloroform: methanol $(2: 1)$ until the leaves were bleached. The aqueous content was removed by partitioning with $1 \mathrm{M} \mathrm{KCl}$ and water. The lipid extract was dried under a gentle stream of nitrogen gas and re-dissolved in $0.5 \mathrm{ml}$ of chloroform. Lipid analysis and acyl group identification was carried out with five biological replicates using the automated electrospray ionization-tandem mass spectrometry facility at Kansas Lipidomics Research Center (Welti et al., 2002).

Glucose was quantified as described before (Chanda et al., 2008).

\section{SA, MESA, AND BTH TREATMENTS}

SA and BTH were dissolved in water and the $\mathrm{pH}$ of SA solution was adjusted to 6.5 with $\mathrm{KOH}$. SA and BTH treatments were carried out by spraying $500 \mu \mathrm{M}$, or $100 \mu \mathrm{M}$ solutions, respectively, until runoff. MeSA (Sigma-Aldrich, Inc.) was dissolved in $100 \mu \mathrm{l}$ of methanol and diluted in water to $100 \mu \mathrm{M}$ working concentration.

\section{PATHOGEN INFECTIONS}

Inoculations with bacterial pathogen $P$. syringae were conducted as described before (Kachroo et al., 2005). The bacterial cultures were grown overnight in King's B medium (King et al., 1954) containing $50 \mu \mathrm{g} / \mathrm{ml}$ of rifampicin and/or kanamycin. The cells were washed and suspended in $10 \mathrm{mM} \mathrm{MgCl}_{2}$. The bacterial suspension was injected into the abaxial surface of the leaf using needle-less syringe. Three disks from the inoculated leaves were collected and homogenized in $10 \mathrm{mM} \mathrm{MgCl}_{2}$. The extract was diluted and appropriate dilutions were plated on King's B medium. For analysis of SAR, the primary leaves were inoculated with $\mathrm{MgCl}_{2}$ or the avr bacteria $\left(10^{7} \mathrm{CFU} \mathrm{ml}{ }^{-1}\right)$ and $48 \mathrm{~h}$ later the distal leaves were inoculated with vir bacteria $\left(10^{5} \mathrm{CFU} \mathrm{ml}{ }^{-1}\right)$. Unless noted 
otherwise, samples from the distal leaves were harvested at $3 \mathrm{dpi}$ and monitored for growth of virulent bacteria.

Colletotrichum higginsianum Sacc. (IMI 349063) and B. cinerea were maintained on potato dextrose agar (PDA; Difco) and V8 medium (Kent et al., 2008), respectively. Four-week-old Arabidopsis plants were used for both spray and spot inoculations. Fungal spores were harvested by scrapping the surface of cultures maintained on PDA or V8 plates, washed three to four times with sterile water, quantified using a hemocytometer, and suspended at concentrations of $10^{4}$ to $10^{6}$ spores $/ \mathrm{ml}$. For spot inoculations, $10 \mu \mathrm{l}$ of spore suspension was used to inoculate Arabidopsis leaves. After inoculations, the plants were transferred to a PGV36 Conviron walk-in chamber and covered with a plastic dome to maintain high humidity. Disease symptoms were scored between 4 and $11 \mathrm{dpi}$. A digital Vernier caliper was used to measure lesion size in spotinoculated leaves. Each experiment was repeated at least twice and each included 30-50 individual plants. Statistical significance was determined using Student's $t$-test.

\section{COLLECTION OF PETIOLE EXUDATE}

Petiole exudate was collected as described earlier (Maldonado et al., 2002). In brief, plants were induced for SAR by inoculation with $P$. syringae containing avrRpt2 $\left(10^{6} \mathrm{CFU} \mathrm{ml}^{-1}\right)$. Twelve $24 \mathrm{~h}$ later, petioles were excised, surface sterilized in 50\% ethanol, $0.0006 \%$ bleach, rinsed in sterile $1 \mathrm{mM}$ EDTA and submerged in $\sim 1.9 \mathrm{ml}$ of $1 \mathrm{mM}$ EDTA and $100 \mu \mathrm{g} \mathrm{ml}^{-1}$ ampicillin. Exudates were collected over $48 \mathrm{~h}$ and infiltrated into healthy plants. Infiltrated leaves were harvested after 2 days for $P R-1$ gene expression studies. For SAR studies, vir pathogen was inoculated in the distal leaves 2 days after infiltration of exudate.

\section{TOLUIDINE BLUE STAINING}

Leaf samples were taken from 4-week-old plants grown on soil and stained with toluidine blue staining was carried out as described earlier (Tanaka et al., 2004). Each genotype was tested in five to six independent experiments with a total of 30-50 leaves stained.

\section{MICROSCOPY, CHLOROPHYLL LEACHING, AND WATER LOSS}

For SEM analysis both abaxial and adaxial surface of the leaf samples was mounted on sample holder with $12 \mathrm{~mm}$ conductive carbon tabs (Ted Pella, Inc.), sputter-coated with gold-palladium and observed on a Hitachi S-3200 SEM, with and without backscatter detector at 5 and $20 \mathrm{kV}$. Two to three leaves were observed per genotype.

For TEM analysis leaves were fixed in paraformaldehyde and embedded in epon-araldite. Leaves were sectioned on a ReichertJung Ultracut E microtome with a Diatome diamond knife and observed under a Philips Tecnai Biotwin 12 TEM. Three to four sections were analyzed per genotype.

For chlorophyll leaching assays, $100 \mathrm{mg}$ of leaves were weighed and gently agitated, in dark, at room temperature in tubes

\section{REFERENCES}

Attaran, E., Zeier, T. E., Griebel, T., and Zeier, J. (2009). Methyl salicylate production and jasmonate signaling are not essential for systemic acquired resistance

containing $80 \%$ ethanol. Absorbance of each sample was measured at 664 and 647 and micromolar concentration of total chlorophyll per gram of fresh weight was calculated using the formula: total micromoles chlorophyll $=7.93\left(\mathrm{~A}_{664}\right)+19.3\left(\mathrm{~A}_{647}\right)$.

For water loss in response to drought treatment, 4-week-old plants were left unwatered until the soil dried completely. The leaf weight was measured from $\sim 50$ leaves.

\section{ANALYSIS OF WAX AND CUTIN COMPONENTS}

For analysis of the wax component, $500 \mathrm{mg}$ of 4-week-old leaves were immersed in $10 \mathrm{ml}$ of chloroform for $10 \mathrm{~s}$. The leaves were rinsed once more with $10 \mathrm{ml}$ of chloroform. An internal standard ( $100 \mu \mathrm{g}$ of $n$-tetracosane) was added and the sample volume was evaporated under a gentle steam of nitrogen. The samples were dried under a stream of nitrogen gas and methylated with diazomethane, dried again, and derivatizated with $100 \mu$ l of acetic anhydride in $100 \mu \mathrm{l}$ of pyridine and the sealed tubes were incubated for $60 \mathrm{~min}$ at $60^{\circ} \mathrm{C}$. The samples were again dried under a stream of nitrogen and dissolved in $1 \mathrm{ml}$ of acetonitrile. Samples $(1 \mu \mathrm{l})$ were injected into an HP-5 column (injection temperature $250^{\circ} \mathrm{C}$ ) of $\mathrm{GC}$ equipped with flame ionization detector (temperature $\left.300^{\circ} \mathrm{C}\right)$. The same samples were also run on an HP-5 column $(30 \mathrm{~mm} \times 0.32 \mathrm{~mm} \times 0.25 \mathrm{~mm}$ film thickness $)$ on a GC equipped with MS. Various components were identified based on their retention time as compared to standards and by MS analysis. Quantification was based on flame ionization detector peak areas as compared to the peak areas of the internal standard tetracosane added prior to derivatization.

Cutin monomer composition and content were determined using sodium methoxide-catalyzed transmethylation method followed by acetylation of the hydroxyl groups with acetic anhydride and GC-MS slightly modified from previously described (Bonaventure et al., 2004; Molina et al., 2006). After methanolysis, the methylene dichloride extract of cutin monomers were washed with $0.9 \%$ potassium chloride instead of $0.5 \mathrm{M}$ sodium chloride. For GC-MS analysis, the FAME capillary column used was as described in wax analysis with helium carrier gas at $1 \mathrm{ml} \mathrm{min}^{-1}$. The MS was run in scan mode over 35-450 amu (electron impact ionization).

\section{ACKNOWLEDGMENTS}

We thank John Johnson for help with gas chromatography, Ludmila Lapchyk for technical help Mee-Len Chye for useful discussions, Larry Rice for help with SEM and Mary Gail Engle for help with TEM. We thank ABRC for ACBP KO lines. We thank Kansas Lipidomics Research Center Analytical Laboratory and its support from National Science Foundation's EPSCoR program, under grant number EPS-0236913 with matching support from the State of Kansas through Kansas Technology Enterprise Corporation and Kansas State University. This work by supported by grants from NSF (MCB\#0421914, IOS\#0749731) and USDA-NRI (2004-03287).

Arabidopsis leads to a strong resistance to Botrytis cinerea. EMBO J.26, 2158-2168.

Boller, T., Gehri, A., Mauch, F., and Vogeli, U. (1983). Chitinase in bean leaves: induction by ethylene, purification, properties, and possible function Phaseolus vulgaris, antibiotic function, defense capacity of plant cells against pathogens. Planta 157, 22-31. 
Bonaventure, G., Beisson, F., Ohlrogge, J., and Pollard, M. (2004). Analysis of the aliphatic monomer composition of polyesters associated with Arabidopsis epidermis: occurrence of octadeca-cis-6,cis-9-diene1,18-dioate as the major component. Plant J. 40, 920-930.

Büttner, N., and Singh, K. B. (1997). Arabidopsis thaliana ethyleneresponsive element binding protein (AtEBP), an ethylene-inducible, GCC box DNA-binding protein interacts with an ocs element binding protein. Proc. Natl. Acad. Sci. U.S.A. 94, 5961-5966.

Carr, J. P., Dixon, D. C., Nikolau, B. J., Voelkerding, K. V., and Klessig, D. F. (1987). Synthesis and localization of pathogenesis-related proteins in tobacco. Mol. Cell. Biol. 7, 1580-1583.

Chanda, B., Venugopal, S. C., Kulshrestha, S., Navarre, D., Downie, B., Vaillancourt, L., et al. (2008). Glycerol-3-phosphate levels are associated with basal resistance to the hemibiotrophic fungus Colletotrichum higginsianum in Arabidopsis. Plant Physiol. 147, 2017-2029.

Chanda, B., Xia, Y., Mandal, M., Yu, K., Sekine, K., Gao, Q.-M., et al. (2011). Glycerol-3-phosphate, a critical mobile inducer of systemic immunity in plants. Nat. Genet. 43, 421-427.

Chandra-Shekara, A. C., Gupte, M., Navarre, D. A., Raina, R., Klessig, D. F., and Kachroo, P. (2006). Lightdependent hypersensitive response and resistance signaling against the turnip crinkle virus in Arabidopsis. Plant J. 45, 320-335.

Chaturvedi, R., Krothapalli, K., Makandar, R., Nandi, A., Sparks, A., Roth, M., et al. (2008). Plastid omega3-fatty acid desaturasedependent accumulation of a systemic acquired resistance inducing activity in petiole exudates of Arabidopsis thaliana is independent of jasmonic acid. Plant J. 54, 106-117.

Chaturvedi, R., Venables, B., Petros, R., Nalam, V., Li, M., Wang, X., et al. (2012). An abietane diterpenoid is a potent activator of systemic acquired resistance. Plant J. 71, 161-172.

Chen, Q. F., Xiao, S., and Chye, M. L. (2008). Overexpression of the Arabidopsis 10-kilodalton acyl-CoAbinding protein ACBP6 enhances freezing tolerance. Plant Physiol. 148, 304-315.

Chye, M. L. (1998). Arabidopsis cDNA encoding a membrane-associated protein with an acyl-CoA binding domain. Plant Mol. Biol. 38, 827-838.

Dempsey, D. A., and Klessig, D. F. (2012). SOS - too many signals for systemic acquired resistance? Trends Plant Sci. Available at: http://dx.doi. org/10.1016/j.tplants.2012.05.011

Doares, S. H., Narvaez-Vasquez, J., Conconi, A., and Ryan, C. A. (1995). Salicylic acid inhibits synthesis of proteinase inhibitors in tomato leaves induced by systemin and jasmonic acid. Plant Physiol. 108, 1741-1746.

Dong, X. (2001). Genetic dissection of systemic acquired resistance. Curr. Opin. Plant Biol. 4, 309-314.

Gaffney, T., Friedrich, L., Vernooij, B., Negmtto, D., Nye, G., Uknes, S., et al. (1993). Requirement of salicylic acid for the induction of systemic acquired resistance. Science 261,754-756.

Glazebrook, J., Chen, W., Estes, B., Chang, H. S., Nawrath, C., Metraux, J. P., et al. (2003). Topology of the network integrating salicylate and jasmonate signal transduction derived from global expression phenotyping. Plant J. 34, 217-228.

Jung, H. W., Tschaplinkski, T. J., Wang, L., Glazebrook, J., and Greenberg, J. T. (2009). Priming in systemic plant immunity. Science 324, 89-91.

Kachroo, A., Daqi, F., Havens, W., Navarre, D., Kachroo, P., and Ghabrial, S. (2008). An oleic acidmediated pathway induces constitutive defense signaling and enhanced resistance to multiple pathogens in soybean. Mol. Plant Microbe Interact. 21, 564-575.

Kachroo, A., and Kachroo, P. (2007). "Salicylic acid-, jasmonic acidand ethylene-mediated regulation of plant defense signaling. Genet. Eng. (N. Y.) 28, 55-83.

Kachroo, A., and Kachroo, P. (2009). Fatty acid-derived signals in plant defense. Annu. Rev. Phytopathol. 47, 153-176.

Kachroo, A., Lapchyk, L., Fukushigae, H., Hildebrand, D., Klessig, D., and Kachroo, P. (2003). Plastidial fatty acid signaling modulates salicylic acid- and jasmonic acidmediated defense pathways in the Arabidopsis ssi2 mutant. Plant Cell 12, 2952-2965.

Kachroo, A., Shanklin, J., Lapchyk, L., Whittle, E., Hildebrand, D., and Kachroo, P. (2007). The Arabidopsis stearoyl-acyl carrier proteindesaturase family and the contribution of leaf isoforms to oleic acid synthesis. Plant Mol. Biol. 63, 257-271.

Kachroo, A., Venugopal, S. C., Lapchyk, L., Falcone, D., Hildebrand, D., and
Kachroo, P. (2004). Oleic acid levels regulated by glycerolipid metabolism modulate defense gene expression in Arabidopsis. Proc. Natl. Acad. Sci. U.S.A. 101, 5152-5257.

Kachroo, P., Shanklin, J., Shah, J., Whittle, E. J., and Klessig, D. F. (2001). A Fatty acid desaturase modulates the activation of defense signaling pathways in Plants. Proc. Natl. Acad. Sci. U.S.A. 98, 9448-9453.

Kachroo, P., Venugopal, S. C., Navarre, D. A., Lapchyk, L., and Kachroo, A. (2005). Role of salicylic acid and fatty acid desaturation pathways in ssi2-mediated signaling. Plant Physiol. 139, 1717-1735.

Kent, C. R., and Ortiz-Bermúdez, P., Giles, S. S., Hull, C. M. (2008). Formulation of a defined V8 medium for induction of sexual development of Cryptococcus neoformans. Appl. Environ. Microbiol. 74, 6248-6253.

King, E. D., Ward, M. K., and Raney, D. E. (1954). Two simple media for the demonstration of pyocyanin and fluorescin. J. Lab. Clin. Med. 44, 301, 1954.

Kragelund, B. B., Andersen, K. V., Madsen, J. C., Knudsen, J., and Poulsen, F. M. (1993). Three-dimensional structure of the complex between acyl-coenzyme A binding protein and palmitoyl-coenzyme A. J. Mol. Biol. 230, 1260-1277.

Kunkel, B. N., and Brooks, D. M. (2002). Cross talk between signaling pathways. Curr. Opin. Plant Biol. 5, 325-331.

Kurdyukov, S., Faust, A., Nawrath, C., Bär, S., Voisin, D., Efremova, N., et al. (2006). The epidermisspecific extracellular BODYGUARD controls cuticle development and morphogenesis in Arabidopsis. Plant Cell 18, 321-339.

Li, H. Y., and Chye, M. L. (2003). Membrane localization of Arabidopsis acyl-CoA binding protein ACBP2. Plant Mol. Biol. 51, 483-492.

Li, H. Y., Xiao, S., and Chye, M.-L. (2008). Ethylene- and pathogeninducible Arabidopsis acyl-CoA binding protein 4 interacts with an ethylene-responsive element binding protein. J. Exp. Bot. 59, 3997-4006.

Li, Y., Beisson, F., Koo, A. J. K., Molina, I., Pollard, M., and Ohlrogge, J. (2007). Identification of acyltransferases required for cutin biosynthesis and production of cutin with suberin-like monomers. Proc. Natl. Acad. Sci. U.S.A. 104, 18339-18344.

Loon, L. C. V., Gerritsen, Y. A. M., and Ritter, C. E. (1987). Identification, purification, and characterization of pathogenesis-related proteins from virus-infected Samsun NN tobacco leaves. Plant Mol. Biol. 9, 593-609.

Maldonado, A. M., Doerner, P., Dixon, R. A., Lamb, C. J., and Cameron, R. K. A. (2002). Putative lipid transfer protein involved in systemic resistance signaling in Arabidopsis. Nature 419, 399-403.

Mandal, M. K., Chanda, B., Xia, Y., Yu, K., Sekine, K., Gao, Q.-M., et al. (2011). Glycerol-3-phosphate and systemic immunity. Plant Signal. Behav. 6, 1871-1874.

Mandal, M. K., Chandra-Shekara, A. C., Jeong, R.-D., Yu, K., Zhu, S., Chanda, B., et al. (2012). Oleic aciddependent modulation of NITRIC OXIDE ASSOCIATED 1 protein levels regulates nitric oxide-mediated defense signaling in Arabidopsis. Plant Cell 24, 1654-1674.

Molina, I., Bonaventure, G., Ohlrogge, J., and Pollard, M. (2006). The lipid polyester composition of Arabidopsis thaliana and Brassica napus seeds. Phytochemistry 67, 2597-2610.

Moreau, P., Bessoule, J. J., Mongrand, S., Testet, T., Vincent, P., and Cassagne, C. (1998). Lipid trafficking in plant cells. Prog. Lipid Res. 37, 371-391.

Ohlrogge, J., and Browse, J. (1995). Lipid biosynthesis. Plant Cell 7, 957-970.

Park, S.-W., Kaimoyo, E., Kumar, D., Mosher, S., and Klessig, D. F. (2007). Methyl salicylate is a critical mobile signal for plant systemic acquired resistance. Science 318, 113-116.

Pollard, M., Beisson, F., Li, Y., and Ohlrogge, J. B. (2008). Builiding lipid barriers: biosynthesis of cutin and suberin. Trends Plant Sci. 13, 236-246.

Rasmussen, J. B., Hammerschmidt, R., and Zook, M. N. (1991). Systemic induction of salicylic acid accumulation in cucumber after inoculation with Pseudomonas syringae pv syringae. Plant Physiol. 97, 1342-1347.

Robert-Seilaniantz, A., Grant, M., and Jones, J. D. G. (2011). Hormone crosstalk in plant disease and defense: more than just jasmonatesalicylate antagonism. Annu. Rev. Phytopathol. 49, 317-343.

Schnurr, J., Shockey, J., and Browse, J. (2004). The acyl-CoA synthetase encoded by LACS2 is essential for normal cuticle development in Arabidopsis. Plant Cell 16, 629-642.

Seskar, M., Shulaev, V., and Raskin, I. (1998). Endogenous methyl salicylate in pathogen-inoculated tobacco plants. Plant Physiol. 116, 387-392.

Smith-Becker, J., Marois, E., Huguet, E. J., Midland, S. L., Sims, J. J., and Keen, 
N. T. (1998). Accumulation of salicylic acid and 4-hydroxybenzoic acid in phloem of cucumber during systemic acquired resistance is preceded by a transient increase in phenylalanine ammonia-lyase activity in petioles and stems. Plant Physiol. 116, 231-238.

Tanaka, T., Tanaka, H., Machida, C., Watanabe, M., and Machida, Y. (2004). A new method for rapid visualization of defects in leaf cuticle reveals five intrinsic patterns of surface defects in Arabidopsis. Plant J. 37, 139-146.

Tang, D., Simonich, M. T., and Innes, R. W. (2007). Mutations in LACS2, a long-chain acyl-coenzyme A synthetase, enhance susceptibility to avirulent Pseudomonas syringae but confer resistance to Botrytis cinerea in Arabidopsis. Plant Physiol. 144, 1093-1103.

Truman, W., Bennett, M. H., Kubigsteltig, I., Turnbull, C., and Grant, M. (2007). Arabidopsis systemic immunity uses conserved signaling pathways and is mediated by jasmonates. Proc. Natl. Acad. Sci. U.S.A. 104,1075-1080.

Truman, W., Bennett, M. H., Turnbull, C. G. N., Grant, M. R. (2010). Arabidopsis auxin mutants are compromised in systemic acquired resistance and exhibit aberrant accumulation of various indolic compounds. Plant Physiol. 152, 1562-1573.

Uknes, S., Winter, A. M., Delaney, T., Vernooij, B., Morse, A., Friedrich, L., et al. (1993). Biological induction of systemic acquired resistance in Arabidopsis. Mol. Plant Microbe Interact. 6, 692-698.

Uppalapati, S. R., Ishiga, Y., Doraiswamy, V., Bedair, M., Mittal, S., Chen, J., et al. (2012). Loss of abaxial leaf epicuticular wax in Medicago truncatula irg1/palm1 mutants results in reduced spore differentiation of anthracnose and nonhost rust pathogens. Plant Cell 24, 353-370.

van Wees, S. C. M., De Swart, E. A. M., Van Pelt, J. A., Van Loon, L. C., and Pieterse, C. M. J. (2000). Enhancement of induced disease resistance by simultaneous activation of salicylate- and jasmonatedependent defense pathways in Arabidopsis thaliana. Proc. Natl. Acad. Sci. U.S.A. 97, 8711-8716.

Venugopal, S. C., Jeong, R. D., Mandal, M., Zhu, S., Chandra-Shekara, A. C., Xia, Y., et al. (2009). ENHANCED DISEASE SUSCEPTIBILITY 1 and salicylic acid act redundantly to regulate resistance gene expression and low OLEATE-induced defense signaling. PLoS Genet. 5, e1000545. doi:10.1371/journal.pgen.1000545

Vincente, M. R.-S., and Plasencia, J. (2011). Salicylic acid beyond defense: its role in plant growth and development. J. Exp. Bot. 62, 3321-3338.

Voisin, D., Nawrath, C., Kurdyukov, S., Franke, R.B., Reina-Pinto, J. J., Efremova, N., et al. (2009). Dissection of the complex phenotype in cuticular mutants of Arabidopsis reveals a role of SERRATE as a mediator. PLoS Genet. 5, e1000703. doi:10.1371/journal.pgen.1000703

Ward, E. R., Uknes, S. J., Williams, S. C., Dincher, S. S., Wiederhold, D. L., Alexander, D. C., et al. (1991). Coordinate gene activity in response to agents that induce systemic acquired resistance. Plant Cell 3, 1085-1094.

Wellesen, K., Durst, F., Pinot, F., Benveniste, I., Netteshein, K., Wisman, E., et al. (2001). Functional analysis of the LACERATA gene of Arabidopsis provides evidence for different roles of fatty acid $\mathrm{w}$ - hydroxylation in development. Proc. Natl. Acad. Sci. U.S.A. 98 9694-9699.

Welti, R., Li, W., Li, M., Sang, Y., Biesiada, H., Zhou, H., et al. (2002). Profiling membrane lipids in plant stress responses: role of phospholipase $\mathrm{D}\{$ alpha $\}$ in freezing-induced lipid changes in Arabidopsis. J. Biol. Chem. 277, 31994-32002.

Xia, Y., Gao, Q.-M., Yu, K., Navarre, D., Hildebrand, D., Kachroo, A., et al. (2009). An intact cuticle in distal tissues is essential for the induction of systemic acquired resistance in plants. Cell Host Microbe 5, 151-165.

Xia, Y., Yu, K., Navarre, D., Seebold, K. Kachroo, A., and Kachroo, P. (2010). The glabral mutation affects cuticle formation and plant responses to microbes. Plant Physiol. 154 833-846.

Xiao, S., and Chye, M. L. (2009). An Arabidopsis family of six acyl-CoAbinding proteins has three cytosolic members. Plant Physiol. Biochem. 47, 479-484.

Xiao, S., and Chye, M. L. (2011). Overexpression of Arabidopsis acylCoA-binding protein 3 enhances NPR1-dependent plant resistance to Pseudomonas syringae $p v$. tomato DC3000. Plant Physiol. 156, 2069-2081.

Xiao, S., Gao, W., Chen, Q. F., Chan, S. W., Zheng, S. X., Ma, J., et al. (2010). Overexpression of Arabidopsis acylCoA-binding protein ACBP3 promotes starvation-induced and agedependent leaf senescence. Plant Cell 22, 1463-1482.

Xiao, S., Gao, W., Chen, Q. F., Ramalingam, S., and Chye, M. L. (2008). Overexpression of membraneassociated acyl-CoA-binding protein ACBP1 enhances lead tolerance in Arabidopsis. Plant J. 54, 141-151.

Yurchenko, O. P., Nykiforuk, C. L., Moloney, M. M., Ståhl, U., Banas, A., Stymme, S., et al. (2009). A 10-kDa acyl-CoA-binding protein (ACBP) from Brassica napus enhances acyl exchange between acyl-CoA and phosphatidylcholine. Plant Biotechnol. J. 7, 602-610.

Yurchenko, O. P., and Weselake, R. J. (2011). Involvement of low molecular mass soluble acyl-CoA-binding protein in seed oil biosynthesis Involvement of low molecular mass soluble acyl-CoA-binding protein in seed oil biosynthesis. N. Biotechnol. 28, 97-109.

Conflict of Interest Statement: The authors declare that the research was conducted in the absence of any commercial or financial relationships that could be construed as a potential conflict of interest.

Received: 15 January 2012; accepted: 17 September 2012; published online: 08 October 2012.

Citation: Xia Y, Yu K, Gao Q-m, Wilson EV, Navarre D, Kachroo $P$ and Kachroo A (2012) Acyl CoA binding proteins are required for cuticle formation and plant responses to microbes. Front. Plant Sci. 3:224. doi: 10.3389/fpls.2012.00224

This article was submitted to Frontiers in Plant Physiology, a specialty of Frontiers in Plant Science.

Copyright (C) 2012 Xia, Yu, Gao, Wilson, Navarre, Kachroo and Kachroo. This is an open-access article distributed under the terms of the Creative Commons Attribution License, which permits use, distribution and reproduction in other forums, provided the original authors and source are credited and subject to any copyright notices concerning any third-party graphics etc. 


\section{APPENDIX}

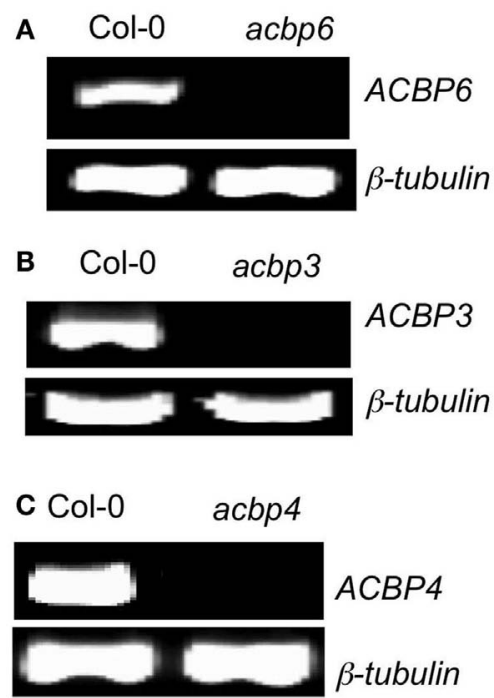

FIGURE A1 | Reverse transcription-PCR analysis showing ACBP transcript levels in wild-type (Col-0) and $\operatorname{acbp3}(\mathrm{A}), \operatorname{acbp} 4(\mathrm{~B})$, and acbp6 (C) mutant plants. The level of $\beta$-tubulin was used as an internal control to normalize the amount of cDNA template. The RT-PCR analysis was repeated with two independent cDNA templates per genotype.

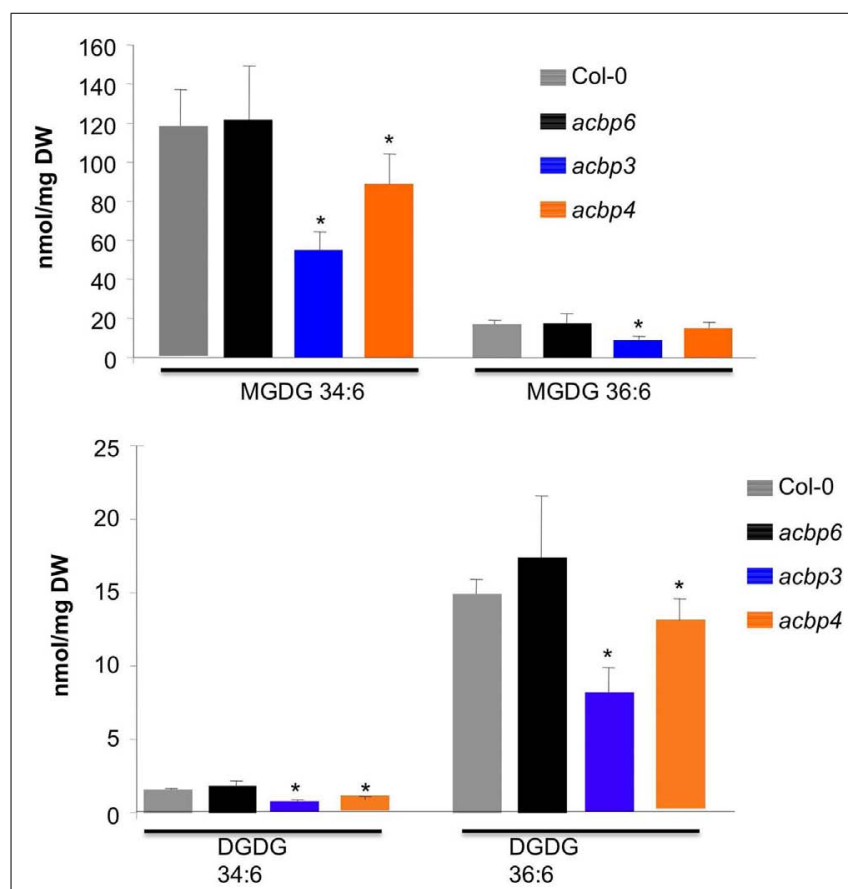

FIGURE A2 | Levels of MGDG and DGDG containing 34:6 or 36:6 FAs in Col-0 and acbp mutant plants. The values are presented as a mean of five replicates. The error bars represent SD. Asterisks denote significant differences with Col-0 ( $t$-test, $P<0.05)$.

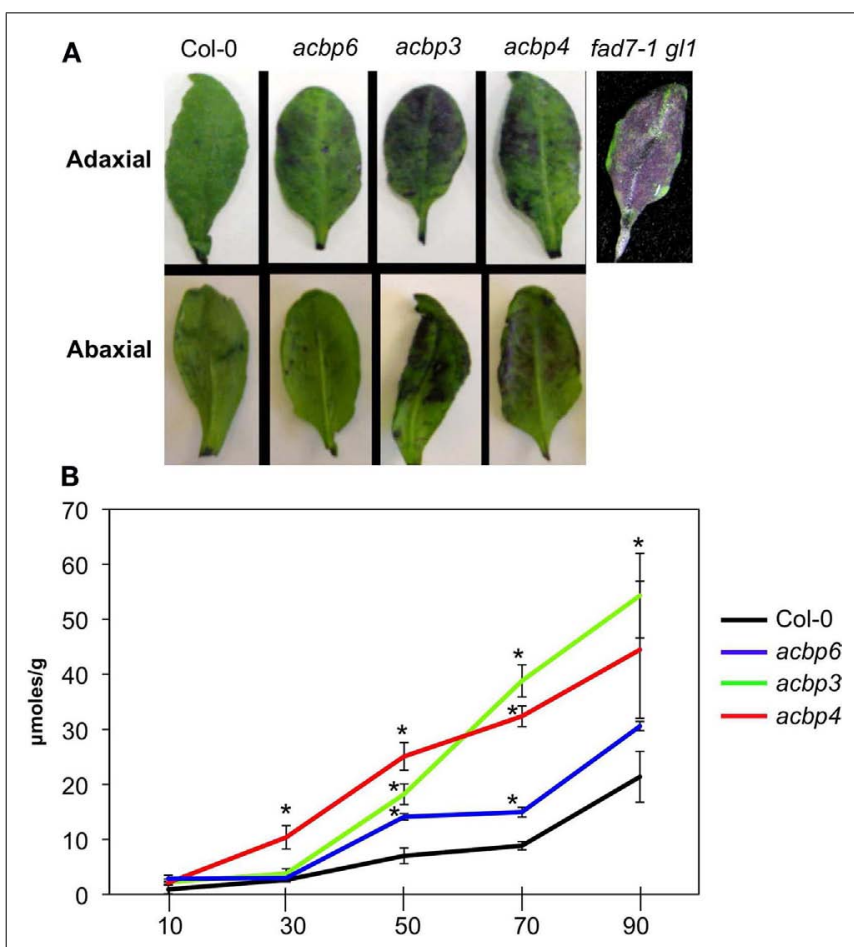

FIGURE A3 | Cuticular phenotypes of acbp plants. (A) Whole leaf toluidine blue staining. Leaves were incubated in the stain for $10 \mathrm{~min}$ and the experiment was repeated four times with similar results. (B) A time-course measurement of chlorophyll leaching in various genotypes at indicated times. The values are presented as a mean of four replicates. The error bars represent SD $(P<0.05)$. The experiment was repeated four times.
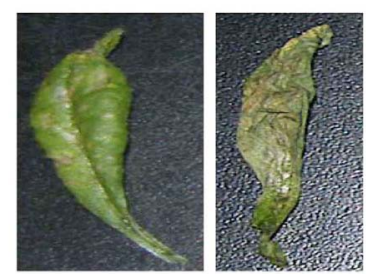

Col-0

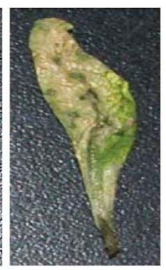

acbp3

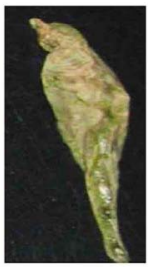

acbp4

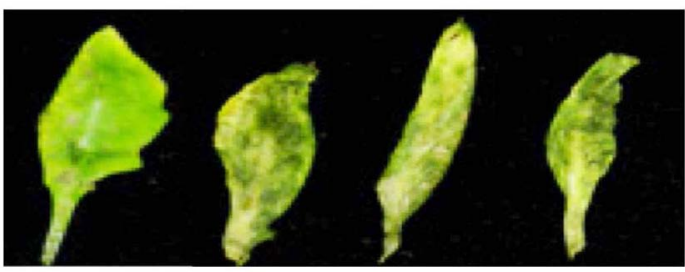

Col-0

acbp3 acbp4

FIGURE A4 | Disease symptoms on indicated genotypes spray-inoculated with $10^{6} \mathrm{spores} / \mathrm{ml}$ of $\boldsymbol{C}$. higginsianum. The experiment was carried out five times, three of which showed enhanced susceptibility in acbp plants, while the remaining two showed wild-like infection phenotypes on acbp plants. The upper and lower panels show two independent experiments that showed enhanced susceptibility in acbp plants 


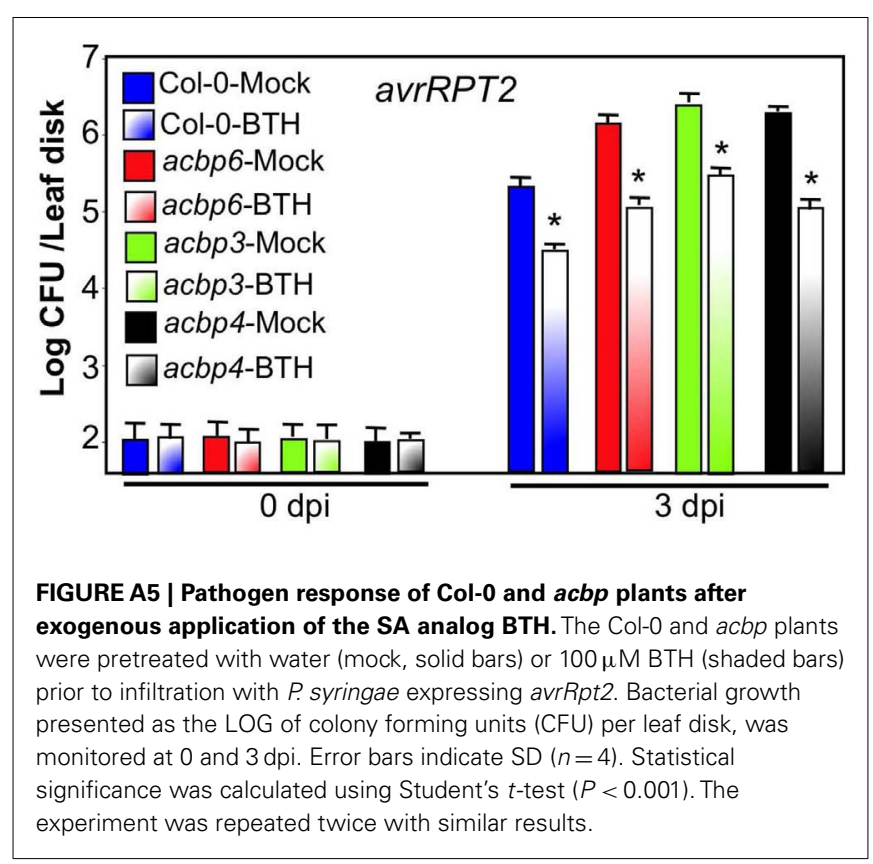

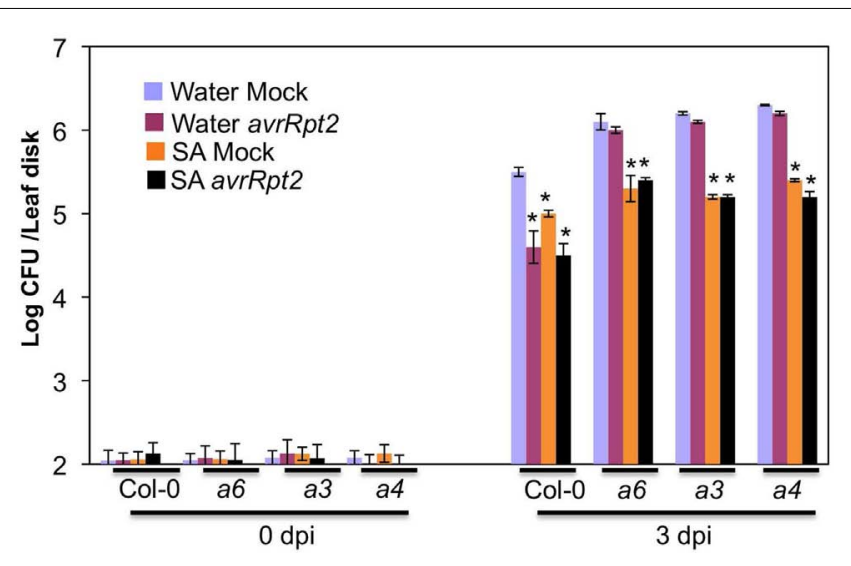

FIGURE A6 | Systemic acquired resistance response in Col-0 and acbp6 (a6), acbp3 (a3), acbp4 (a4) plants, pretreated with water (blue and pink bars) or $50 \mu \mathrm{M}$ SA (orange and black bars) prior to infiltration with $\mathrm{MgCl}_{2}$ (mock, blue, and orange bars) or $\boldsymbol{P}$. syringae expressing avrRpt2 (pink and black bars). Bacterial growth presented as the LOG of colony forming units (CFU) per leaf disk, was monitored at 0 and $3 \mathrm{dpi}$. Error bars indicate $\mathrm{SD}(n=4)$. Asterisks denote statistical differences from water + mock-inoculated plants (blue bars) of corresponding genotype, calculated using Student's $t$-test $(P<0.001)$. 